ARTICLE

\title{
trans-Translation inhibitors bind to a novel site on the ribosome and clear Neisseria gonorrhoeae in vivo
}

Zachary D. Aron ${ }^{1,8}$, Atousa Mehrani ${ }^{2,8}$, Eric D. Hoffer 3,8 , Kristie L. Connolly (1) 4 , Pooja Srinivas ${ }^{3,5}$, Matthew C. Torhan', John N. Alumasa (1) ${ }^{6}$, Mynthia Cabrera ${ }^{6}$, Divya Hosangadi6, Jay S. Barbor', Steven C. Cardinale ${ }^{1}$, Steven M. Kwasny', Lucas R. Morin (1) 1, Michelle M. Butler1, Timothy J. Opperman', Terry L. Bowlin ${ }^{1}$, Ann Jerse ${ }^{4}$, Scott M. Stagg (1) ${ }^{2,7}$, Christine M. Dunham (1) ${ }^{3 凶}$ \& Kenneth C. Keiler (i) ${ }^{6 凶}$

Bacterial ribosome rescue pathways that remove ribosomes stalled on mRNAs during translation have been proposed as novel antibiotic targets because they are essential in bacteria and are not conserved in humans. We previously reported the discovery of a family of acylaminooxadiazoles that selectively inhibit trans-translation, the main ribosome rescue pathway in bacteria. Here, we report optimization of the pharmacokinetic and antibiotic properties of the acylaminooxadiazoles, producing MBX-4132, which clears multiple-drug resistant Neisseria gonorrhoeae infection in mice after a single oral dose. Single particle cryogenic-EM studies of non-stop ribosomes show that acylaminooxadiazoles bind to a unique site near the peptidyl-transfer center and significantly alter the conformation of ribosomal protein bL27, suggesting a novel mechanism for specific inhibition of transtranslation by these molecules. These results show that trans-translation is a viable therapeutic target and reveal a new conformation within the bacterial ribosome that may be critical for ribosome rescue pathways.

\footnotetext{
${ }^{1}$ Microbiotix, Inc. One Innovation Dr., Worcester, MA, USA. ${ }^{2}$ Department of Chemistry and Biochemistry, Florida State University, Tallahassee, FL, USA.

${ }^{3}$ Department of Biochemistry and Emory Antibiotic Resistance Center, Emory University School of Medicine, Atlanta, GA, USA. ${ }^{4}$ Department of Microbiology and Immunology, Uniformed Services University, Bethesda, MD, USA. ${ }^{5}$ Molecular \& Systems Pharmacology Graduate Program, Emory University, Atlanta, GA, USA. ${ }^{6}$ Department of Biochemistry \& Molecular Biology, Penn State University, University Park, PA, USA. ${ }^{7}$ Institute of Molecular Biophysics, Florida State University, Tallahassee, FL, USA. ${ }^{8}$ These authors contributed equally: Zachary D. Aron, Atousa Mehrani, Eric D. Hoffer.

凶email: cmdunha@emory.edu; kkeiler@psu.edu
} 
A ntibiotic-resistant bacterial pathogens pose a substantial threat to human health and are projected to cause up to 10 million deaths per year by 2050 if new antibiotics are not developed ${ }^{1}$. Among the five most dangerous "Urgent Threats" identified by the CDC is drug-resistant Neisseria gonorrhoeae, which infects $>500,000$ people per year in the US 2 . New antibiotics must be developed to treat these drug-resistant infections. Bacterial ribosome rescue pathways have been proposed as potential antibiotic targets because these pathways are essential in bacterial pathogens but are highly dissimilar from cytoplasmic mechanisms to disassemble non-stop ribosomes in eukaryotes $^{3}$.

Bacterial ribosomes frequently stall at the $3^{\prime}$ end of mRNAs lacking an in-frame stop codon due to physical or nucleolytic damage to the mRNA or premature termination of transcription ${ }^{4}$. These "non-stop" ribosomes must be rescued to maintain protein synthesis capacity and cell viability ${ }^{4}$. All bacterial species that have been studied use trans-translation as the primary ribosome rescue pathway. During trans-translation, transfer-messenger RNA (tmRNA) and the protein $S m p B$ recognize non-stop ribosomes and use tRNA-like and mRNA-like properties of tmRNA to add a short sequence to the nascent polypeptide and terminate translation at a stop codon within tmRNA ${ }^{4}$. In some bacteria, including $N$. gonorrhoeae, tmRNA and $\mathrm{SmpB}$ are essential ${ }^{5,6}$. Other species have an alternative ribosome rescue factor (ArfA, ArfB, ArfT, or BrfA) that acts as a backup system for rescuing ribosomes when trans-translation activity is not sufficient ${ }^{7-10}$.
Deletions of the alternative ribosome rescue factors and tmRNA or SmpB are synthetically lethal, indicating that at least one mechanism for ribosome rescue is required for bacterial viability ${ }^{5}$.

A family of acylaminooxadiazoles identified in a highthroughput screen for inhibitors of trans-translation in Escherichia coli has broad-spectrum antibiotic activity in vitro ${ }^{3,11}$. Experiments in E. coli and Mycobacterium smegmatis showed that KKL-2098, a cross-linkable acylaminooxadiazole derivative, bound $23 \mathrm{~S}$ rRNA near the peptidyl-transfer center (PTC), suggesting that these molecules inhibit trans-translation by binding the ribosome ${ }^{11}$. Based on these data, we sought to optimize the acylaminooxadiazole activity against $N$. gonorrhoeae and establish the basis for selective inhibition of trans-translation.

\section{Results}

Development of a trans-translation inhibitor that is active in animals. Evaluation of in vitro pharmacokinetic properties of the original hit, KKL-35, revealed that the amide bond is rapidly hydrolyzed in liver microsomes, making it unsuitable for use in animals (Fig. 1, Supplementary Table 1). To enable animal studies, $>500$ analogs of KKL-35 were designed and evaluated for potency, toxicity, and pharmacokinetic properties (Fig. 1, Supplementary Table 1). Compound potency, assessed by minimum inhibitory concentration (MIC) against N. gonorrhoeae and activity $\left(\mathrm{EC}_{50}\right)$ in a trans-translation luciferase reporter assay $^{3}$, was responsive to structural changes, consistent with specific binding of the molecule
A

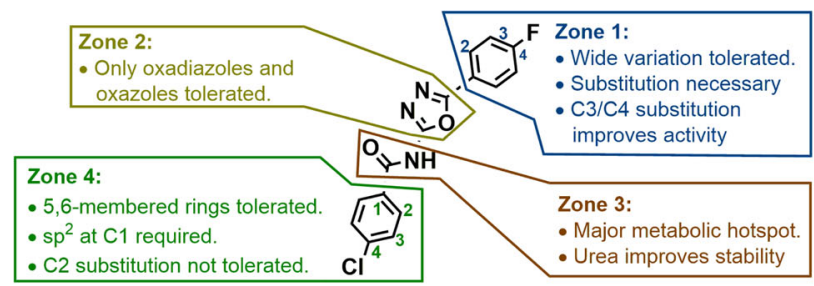

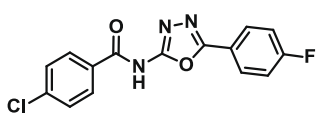

KKL-35

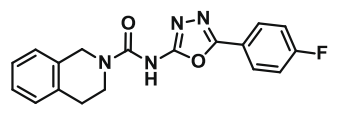

MBX-4132

B

\begin{tabular}{rc} 
in vivo luc-trpAt IC & KKL-35 \\
\hline in vitro trans-translation IC & $0.1 \mu \mathrm{M}$ \\
N. gonorrhoeae H041 MIC & $0.4 \mu \mathrm{M}$ \\
N. gonorrhoeae MIC $\mathrm{C}_{90}$ & $\mathrm{n} .12 \mu \mathrm{d} / \mathrm{ml}$ \\
$\mathrm{CC}_{50}$ & $>100 \mu \mathrm{M}$ \\
solubility (formulated) & $1 \mathrm{mg} / \mathrm{ml}$ \\
MMS (t $1 / 2)$ & $<5 \mathrm{~min}$ \\
murine serum binding & $>99 \%$ \\
Caco-2; $\mathrm{P}_{\text {app }}$ (A to B) & n.d.
\end{tabular}

$\frac{\mathrm{MBX}-4132}{0.6 \mu \mathrm{M}}$
$0.4 \mu \mathrm{M}$
$0.18 \mu \mathrm{g} / \mathrm{ml}$
$0.34 \mu \mathrm{g} / \mathrm{ml}$
$45 \mu \mathrm{M}$
$5 \mathrm{mg} / \mathrm{ml}$
$>120 \mathrm{~min}$
$98 \%$
$11 \times 10^{-6} \mathrm{cms}^{-1}$

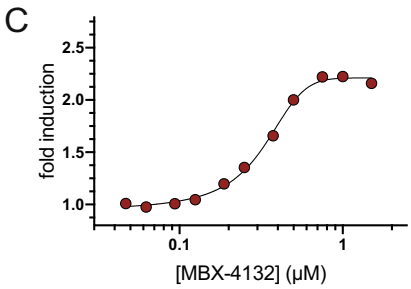

$\mathrm{D}$

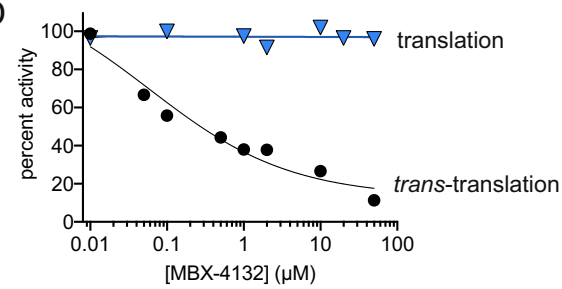

E

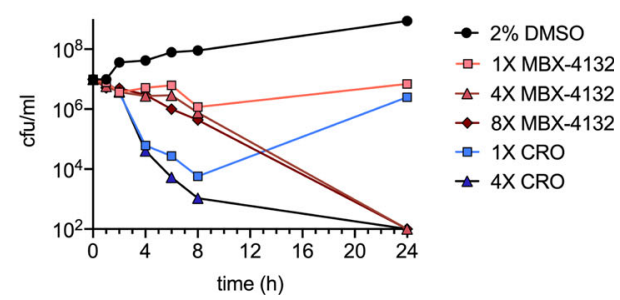

Fig. 1 Optimized acylaminooxadiazoles inhibit trans-translation to kill $\mathbf{N}$. gonorrhoeae. A Zones used to guide synthetic strategy with characteristics that govern activity are indicated, and the structures of KKL-35 and MBX-4132 are shown. B Properties of the initial hit, KKL-35, and optimized inhibitor MBX-

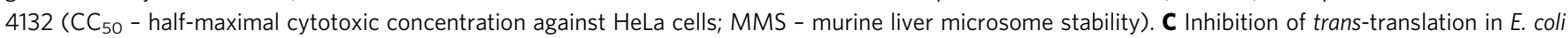
cells was monitored using a non-stop luciferase reporter. The average of two biological repeats is shown. D Inhibition of trans-translation in vitro was assayed using an E. coli S12 extract to express a truncated, non-stop nano-luciferase gene in the presence of a mutant tmRNA that added the remainder of the nano-luciferase protein. Trans-translation activity resulted in luminescence, and addition of MBX-4132 inhibited the reaction (black). As a control, a fulllength nano-luciferase gene was used to demonstrate that $\mathrm{MBX}-4132$ does not inhibit translation (blue). The percentage of activity compared to activity in absence of MBX-4132 is shown from the average of at least two repeats. E Time-kill assays using $N$. gonorrhoeae show that MBX-4132 is bactericidal at $\geq 4 X$ MIC. Ceftriaxone (CRO) was used as a control. Counts below the detection limit (100 cfu/ml) were plotted at $100 \mathrm{cfu} / \mathrm{ml}$. Source data are provided as a Source Data file. 
to the target (Fig. 1, Supplementary Table 1). Conceptually, the compound can be divided into 4 distinct zones (Fig. 1A). The central portion (Zones 2 and 3 ) played a critical role in activity, and the termini (Zones 1 and 4) tolerated changes that facilitated tuning physical properties and potency. A key finding of these experiments was that replacement of the Zone 3 amide with a urea dramatically improved metabolic stability without significantly decreasing potency (Fig. 1, Supplementary Table 1). MBX-4132, a uriedooxadiazole, exhibited excellent stability in both murine liver microsomes $\left(t_{1 / 2}>120 \mathrm{~min}\right.$.) and murine serum $(>99.8 \%$ remaining after $1 \mathrm{~h}$ ) (Fig. 1B, Supplementary Table 2). MBX-4132 also showed excellent permeability through Caco-2 cells, a predictive indicator of oral bioavailability (Fig. 1B, Supplementary Table 2). These data suggested that MBX-4132 could be dosed orally and was likely to be stable in animals. Like KKL-35, MBX-4132 inhibited trans-translation both in the E. coli luciferase reporter assay (Fig. $1 \mathrm{~B}$ ) and in an in vitro reconstituted assay $\left(\mathrm{IC}_{50}=\right.$ $0.4 \mu \mathrm{M}$ ) but did not inhibit translation in vitro (Fig. 1D).

Like the parent acylaminooxadiazole compounds, MBX-4132 exhibited potent broad-spectrum antibiotic activity against Grampositive species and many Gram-negative species, including N. gonorrhoeae (Fig. 1, Supplementary Tables 3 and 4). The prevalence of multiple-drug resistant (MDR) strains of $N$. gonorrhoeae has made infections increasingly difficult to treat ${ }^{2}$. MBX-4132 was highly effective against all tested clinical isolates of $N$. gonorrhoeae, including MDR strains (Fig. 1, Supplementary Table 3), indicating that prevalent resistance mechanisms are not active against MBX-4132. The frequency of spontaneous mutants resistant to $\mathrm{MBX}-4132$ was $<1.2 \times 10^{-9}$, suggesting that emergence of resistance in the clinic is likely to be rare. Time-kill assays demonstrated that MBX-4132 was bactericidal against $N$. gonorrhoeae at concentrations $\geq 4 \mathrm{X}$ MIC (Fig. 1E).

In vitro analyses indicated that MBX-4132 is likely to have low toxicity in mammals. Assays for competitive binding with 45 mammalian receptors, inhibition of 7 cardiac ion channels, inhibition of the 5 major liver CYP450 enzymes, and an Ames assay for genotoxicity revealed only minor inhibition of two mammalian receptors, indicating that there is minimal off-target activity (Supplementary Tables 5 and 6). In addition, high concentrations of MBX-4132 had no effect on mitochondrial membrane polarity in human hepatocytes, although elevated levels of reactive oxygen species (ROS) were observed at cytotoxic compound concentrations (Supplementary Table 7). Likewise, MBX-4132 did not induce differential toxicity against HepG2 cells in the presence of either glucose or galactose, consistent with normal mitochondrial metabolism (Supplementary Table 7). Collectively, these data show that MBX-4132 is appropriate for animal model studies and potentially for human use.

MBX-4132 clears multi-drug resistant $N$. gonorrhoeae from infected mice. The development of a single dose therapy for gonorrhea is clinically important as a means to ensure patient compliance and limit development of resistance ${ }^{12,13}$. As predicted by the in vitro pharmacokinetic assays, MBX-4132 was highly orally bioavailable in mice, exhibiting excellent plasma exposure (area under the curve; AUC), half-life $\left(\mathrm{t}_{1 / 2}\right)$, and a low clearance rate (Supplementary Fig. 1). These data indicate the compound accumulates at high levels and provides prolonged exposure after a single oral dose. The mice exhibited no obvious adverse effects after a single dose of $100 \mathrm{mg} / \mathrm{kg}$ or repeat dosing at $10 \mathrm{mg} / \mathrm{kg}$ (BID, $7 \mathrm{~d}$ ), demonstrating that the compound is tolerated well. Based on these results and the in vitro potency against $N$. gonorrhoeae, we investigated the efficacy of a single oral dose of MBX-4132 in a murine genital tract infection model ${ }^{14-17}$.
To test in vivo efficacy, lower genital tract infection was established with the N. gonorrhoeae clinical isolate H041, an MDR strain that is resistant to at least 7 classes of antibiotics ${ }^{18}$. Infected mice were treated either with vehicle, a single oral dose of $10 \mathrm{mg} / \mathrm{kg}$ MBX-4132, or with daily intraperitoneal injection of $48 \mathrm{mg} / \mathrm{kg}$ gentamicin for 5 days ( $n=20-21$ mice/group). Efficacy was monitored by quantitative culture of $N$. gonorrhoeae from vaginal swabs, and clearance of infection from a mouse was defined as three consecutive days with no detectable N. gonorrhoeae (Fig. 2). Gentamicin was used as a positive control because it is one of the few antibiotics shown to be effective against H041 in vivo, even though it is not orally bioavailable and requires daily dosing ${ }^{15}$. As previously observed, daily intraperitoneal injection of gentamicin was effective against H041, clearing infection in 95\% of treated mice (Fig. 2A). A single oral dose of MBX-4132 also showed significant efficacy, with $80 \%$ of mice completely cleared of infection by 6 days, and a dramatic reduction in bacterial load across all animals (Fig. 2B). These data are the first in vivo proofof-concept that inhibition of trans-translation is a viable antibiotic
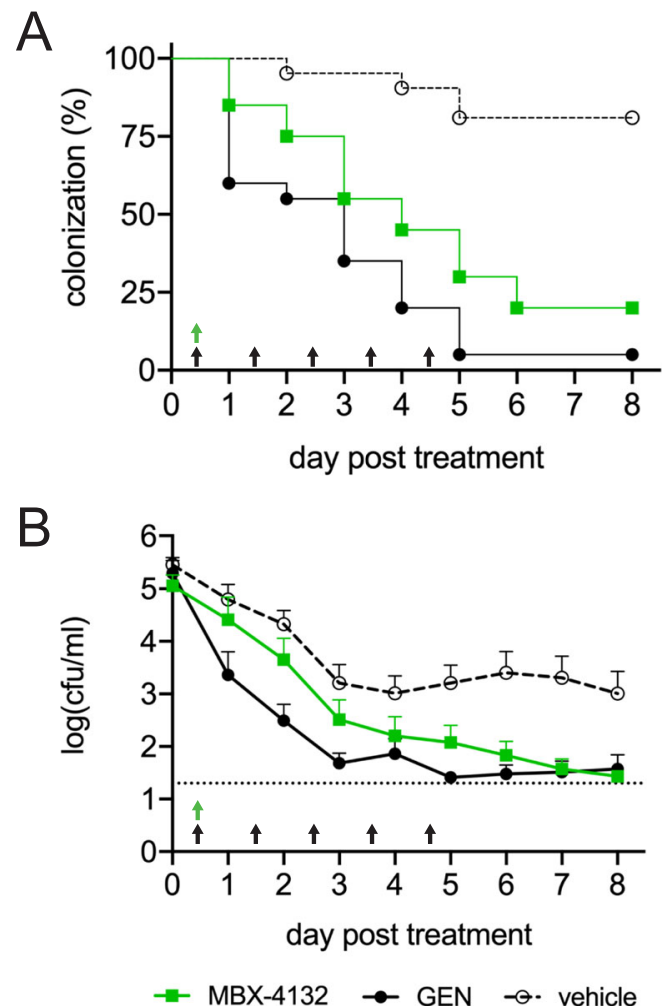

Fig. 2 MBX-4132 clears infection by a multiple-antibiotic resistant $\mathbf{N}$. gonorrhoeae strain in a murine infection model. Mice were infected with $N$. gonorrhoeae $\mathrm{H041}$ for two days and treated with a single oral dose of $10 \mathrm{mg} / \mathrm{kg} \mathrm{MBX}-4132$ or vehicle on day 0 (green arrow), ( $n=20$ mice for MBX-4132 and $n=21$ mice for vehicle). As a positive control, $48 \mathrm{mg} / \mathrm{kg}$ gentamicin (GEN) was administered by intraperitoneal injection beginning on day 0 (5QD, black arrows). A The percentage of infected mice over 8 days post-treatment. Mice that were culture-negative for at least 3 consecutive days were considered to have cleared infection. MBX-4132 and GEN significantly reduced the percent of infected mice compared to vehicle (Mantel-Cox, $p$ < 0.0001). B Mean bacterial burden (cfu/ml) recovered daily following treatment on day $0 . M B X-4132$ and GEN significantly reduced the bacterial burden compared to vehicle (2-way ANOVA with Bonferroni for multiple comparisons, $p<0.0001$ ). Limit of detection $(20 \mathrm{cfu} / \mathrm{ml})$ is denoted by the horizontal dashed line. Error bars indicate standard error of the mean. Source data are provided as a Source Data file. 
A<smiles>C#Cc1ccc(-c2nnc(NC(=O)c3ccc(N)cc3)o2)cc1</smiles>
KKL-2098

B

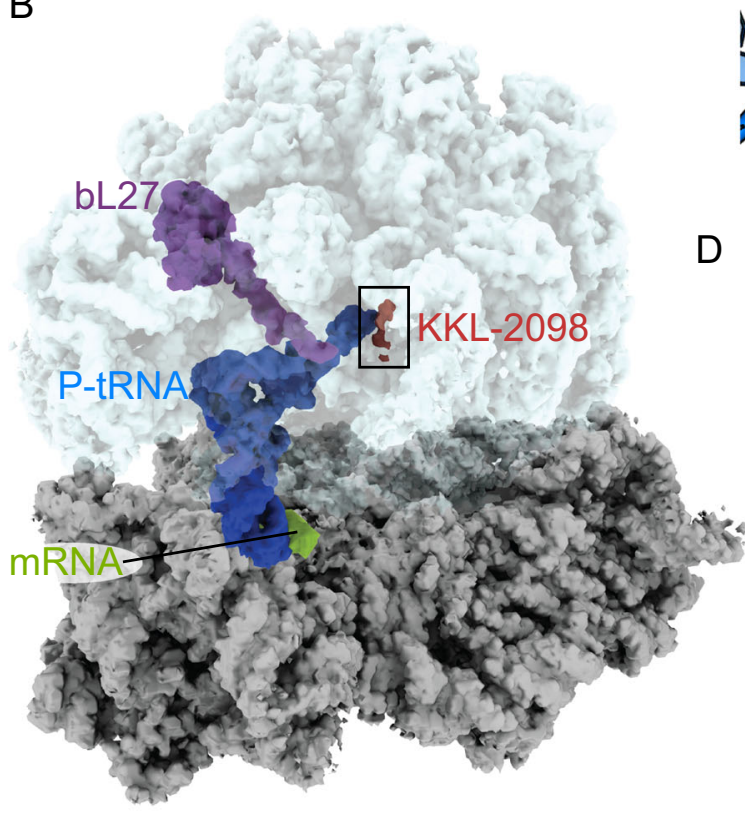

C

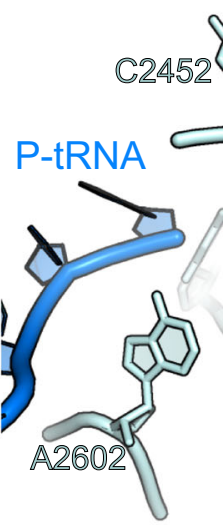

यी।
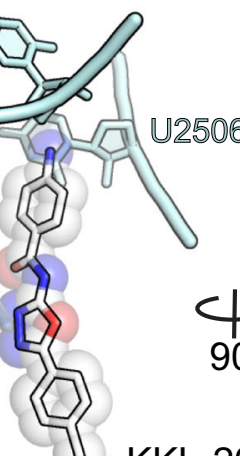

7

KKL-2098
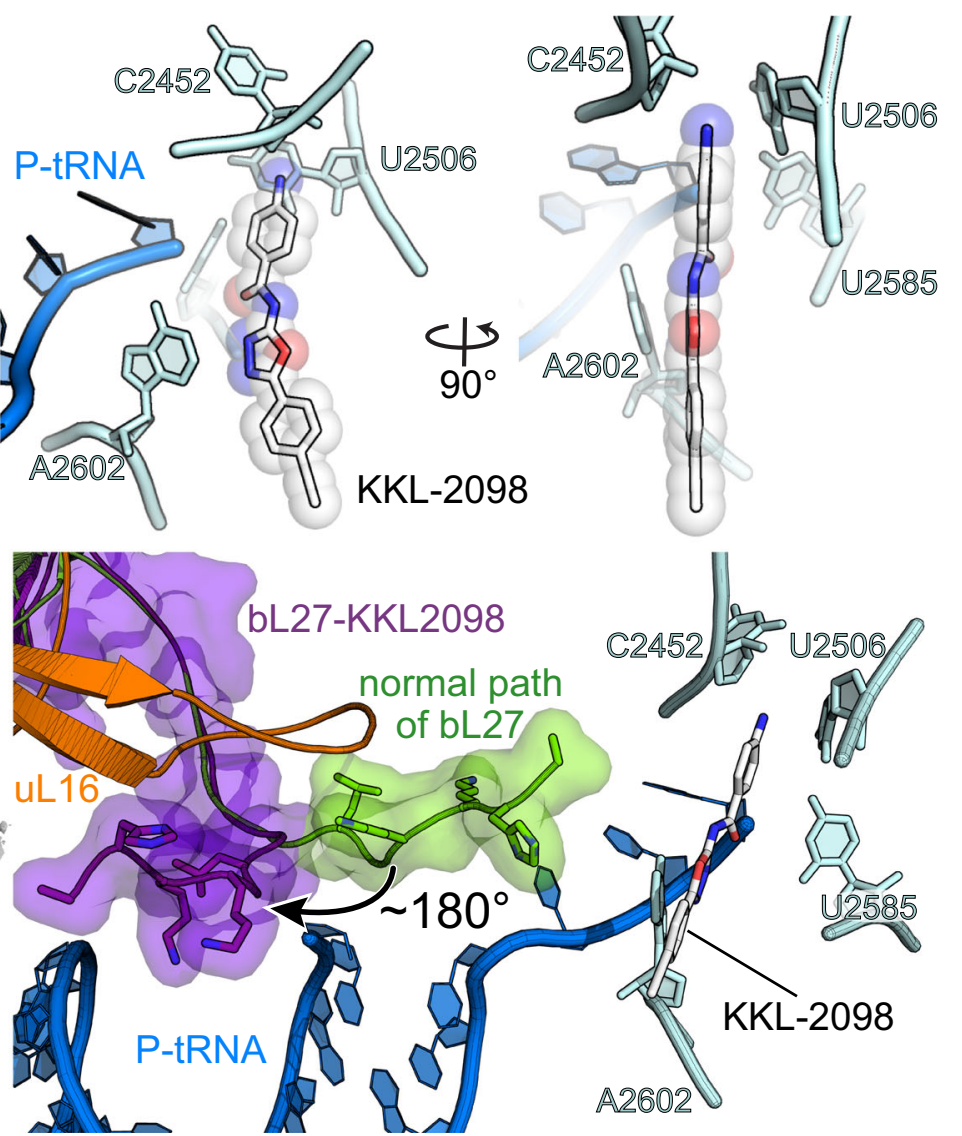

Fig. 3 KKL-2098 binds near the peptidyl transferase center. A The chemical structure of KKL-2098. B The cryo-EM structure of the E. coli $70 S$ non-stop ribosome with P-site tRNA, mRNA, ribosomal protein bL27 and KKL-2098 indicated. C KKL-2098 is positioned close to the peptidyl transferase center adjacent to 23S rRNA A2602, C2452, U2506, and U2585 and the CCA end of the P-site tRNA. D The N terminus of bL27 (purple) moves $180^{\circ}$ to pack against ribosomal protein uL16 and the acceptor arm of the P-site tRNA. The normal position of bL27 in translating ribosomes is shown in green (PDB 6ENU).

strategy and are particularly noteworthy because they were achieved against an MDR strain of gonorrhea following a single oral dose.

Acylaminooxadiazole inhibitors bind near the PTC of nonstop ribosomes. To understand the mechanism of the acylaminooxadiazole antibiotics, we used cryogenic electron microscopy (cryo-EM) to determine the structure of KKL-2098 cross-linked to a non-stop ribosome (Fig. 3, Supplementary Fig. 2, Table 1). In previous in vivo experiments, KKL-2098 crosslinked to 23S rRNA in a small percentage of total ribosomes ${ }^{11}$. For structural studies, we affinity-purified non-stop ribosomes to increase the homogeneity of the sample and the occupancy of KKL-2098. Non-stop ribosomes were generated in E. coli by over-expression of an mRNA containing an RNase III cleavage site before the stop codon. Endogenous RNase III cuts this mRNA in vivo, and translation of the truncated mRNA produces non-stop ribosomes. The mRNA encodes a histidine tag followed by 49 amino acids, such that non-stop ribosomes will have the histidine tag from the nascent polypeptide extending from the exit tunnel, enabling affinity purification. KKL-2098 was added to the culture, UV radiation was used to stimulate cross-linking between KKL-2098 and the ribosomes, and the non-stop ribosomes were affinitypurified, vitrified, and visualized by cryo-EM. 474,382 particles were collected and classified to isolate the $70 \mathrm{~S}$ ribosomes containing a P-site tRNA, and the structure was solved to $3.1 \AA$ resolution (Supplementary Figs. 2-4).

Inspection of the map revealed density consistent with KKL2098 near residue C2452 in the PTC, a 23S rRNA nucleotide shown to crosslink with KKL-2098 in E. coli ${ }^{3}$. The resolution of KKL-2098 was not high enough to distinguish one end of the molecule from the other, but the molecule could be oriented with high confidence based on the following considerations. First, Zone 4 of KKL-2098 contains the moiety that crosslinks to $\mathrm{C} 2452^{3}$, and in its current refined position this end of KKL-2098 is within $2.1 \AA$ of C2452 (Fig. 3C and Supplementary Fig. 5). Second, Zone 1 of KKL-2098, which was highly tolerant of chemical changes (Fig. 1), is in a position where the alkyne does not make any molecular interactions with the ribosome, consistent with its chemical promiscuity. Third, in this orientation N3 of the oxadiazole, which allowed no substitutions (Fig. 1, Supplementary Table 1), is adjacent to A2602, positioned to make hydrogen-bonding or dipole interactions that require the 1,3,4 oxadiazole configuration (note that this oxadiazole configuration has a strong dipole moment $\left.{ }^{19}\right)$. Other molecular interactions between KKL-2098 and the ribosome include the amide oxygen in Zone 3 with the $3^{\prime}$ end of the terminal A76 from the P-site tRNA. Overall, these interactions explain why minor changes in Zones 2 and 3 dramatically reduced potency (Supplementary Table 1). The position of KKL-2098 would clash with tmRNA in the A site, partially overlapping with the phosphate of the terminal adenine (Supplementary Fig. 6), suggesting that the acylaminooxadiazoles may inhibit trans-translation in part either by preventing tmRNA-SmpB binding at the A site or by interfering with tmRNA-SmpB translocation from the A to the P site.

The $\mathbf{N}$ terminus of bL27 is important for inhibition activity. Although no major rearrangements in the rRNA core of the PTC were observed, the $\mathrm{N}$-terminal 7 residues of ribosomal protein 
bL27 ("b" indicates a bacterial specific ribosomal protein ${ }^{20}$ ) move $\sim 180^{\circ}$ from the PTC (Fig. 3D, Supplementary Movie 1). This position is $>25 \AA$ from its position in ribosomes containing a peptidyl-tRNA in the $\mathrm{P}$ site $\mathrm{e}^{21-23}$ (Supplementary Fig. 7, Supplementary Movie 1). As is the case for many ribosomal proteins, the first 20 residues of bL27 form a long extension with no secondary structure and these residues are frequently not resolved in structures of $70 \mathrm{~S}$ ribosomes lacking A-site tRNA. Cross-linking and biochemical studies show that the $\mathrm{N}$ terminus of bL27 extends to the $3^{\prime}$ end of the P-site tRNA and stabilizes product

\begin{tabular}{|c|c|}
\hline & $\begin{array}{l}\text { 70S • P-site tRNA • KKL-2098 } \\
(\text { EMDB-20121) (PDB 60M6) }\end{array}$ \\
\hline \multicolumn{2}{|l|}{ Data collection and processing } \\
\hline Magnification & 59,000 \\
\hline Voltage (kV) & 300 \\
\hline Electron exposure $\left(e-/ \AA^{2}\right)$ & 58 \\
\hline Defocus range $(\mu \mathrm{m})$ & $1.5-3.5$ \\
\hline Pixel size $(\AA)$ & 1.191 \\
\hline Symmetry imposed & $\mathrm{C} 1$ \\
\hline Initial particle images (no.) & 474,382 \\
\hline Final particle images (no.) & 28,121 \\
\hline Map resolution $(\AA)$ & 3.1 \\
\hline FSC threshold & 0.143 \\
\hline Map resolution range $(\AA)$ & 3.1 \\
\hline \multicolumn{2}{|l|}{ Refinement } \\
\hline Initial model used (PDB code) & $5 \mathrm{MDV}$ \\
\hline Model resolution $(\AA)$ & 3.1 \\
\hline FSC threshold & 0.143 \\
\hline Model resolution $(\AA)$ & 3.3 \\
\hline Map sharpening $B$ factor $\left(\AA^{2}\right)$ & 88.04 \\
\hline \multicolumn{2}{|l|}{ Model composition } \\
\hline Non-hydrogen atoms & 144295 \\
\hline Protein residues & 5715 \\
\hline Ligands & KKL: 1 \\
\hline$B$ factors $\left(\AA^{2}\right)$ & $\mathrm{min} / \mathrm{max} /$ mean \\
\hline Protein & $96.44 / 652.55 / 167.47$ \\
\hline Ligand & 152.66 \\
\hline \multicolumn{2}{|l|}{ R.m.s. deviations } \\
\hline Bond lengths $(\AA)$ & 0.007 \\
\hline Bond angles $\left(^{\circ}\right)$ & 0.897 \\
\hline \multicolumn{2}{|l|}{ Validation } \\
\hline MolProbity score & 1.73 \\
\hline Clashscore & 6.66 \\
\hline Poor rotamers (\%) & 0.3 \\
\hline \multicolumn{2}{|l|}{ Ramachandran plot } \\
\hline Favored (\%) & 94.7 \\
\hline Allowed (\%) & 4.22 \\
\hline Disallowed (\%) & 1.12 \\
\hline
\end{tabular}

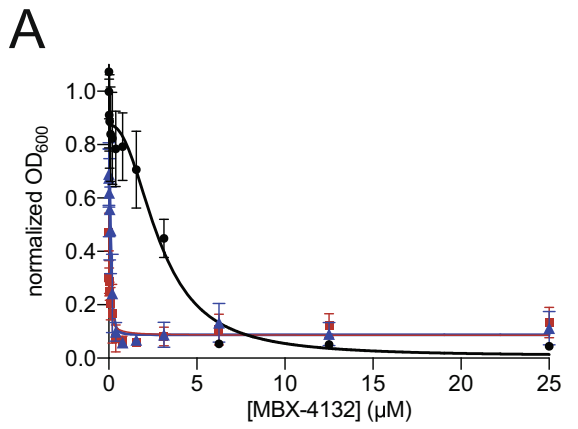

formation of the peptidyl transferase reaction ${ }^{21,24-26}$. Consistent with these data, the $\mathrm{N}$ terminus extends parallel to the $3^{\prime}$ end of the P-site tRNA in structures containing either peptidyl P-site tRNAs or aminoacylated A-site tRNAs ${ }^{21-23}$. In the KKL-2098bound structure, the $\mathrm{N}$ terminus bends $\sim 180^{\circ}$ at Gly7 and packs against ribosomal protein uL16 ("u" indicates a universal ribosomal protein ${ }^{20}$ ) and the acceptor stem of the P-site tRNA. In this position bL27 would not be able to participate in the peptidyl transferase reaction when tmRNA is presented in the A site. The two distinct positions of bL27 suggest that its $\mathrm{N}$ terminus is mobile and its movement may be required for optimal transtranslation activity.

To test whether the position of bL27 plays a role in acylaminooxadiazole activity, we examined the effects of $E$. coli mutants that are truncated by 3 or 6 residues from the $\mathrm{N}$ terminus, preventing bL27 from reaching the PTC. These mutations decrease the rate of translation in vitro, but $E$. coli mutants containing only the truncated bL27 are viable, although they grow slowly ${ }^{24}$. Both mutants were hypersensitive to MBX4132, but not to other antibiotics that target the ribosome, indicating that absence of bL27 from the PTC increases sensitivity to MBX-4132 (Fig. 4).

\section{Discussion}

MBX-4132 can clear MDR N. gonorrhoeae from infected mice after a single oral dose, indicating that the compound is effective under an ideal clinical dosing regimen. The low toxicity against human cells, enzymes, and receptors suggests that MBX-4132 could be developed for clinical treatment of drug-resistant gonorrhea in humans. Taken together, the specific inhibition of trans-translation by acylaminooxadiazoles and significant in vivo efficacy against $N$. gonorrhoeae after a single oral dose, combined with the new chemical structure, support further development of these compounds as promising new antibiotics.

The mechanism of action for the acylaminooxadiazoles is important both for antibiotic development and for fundamental understanding of trans-translation. In particular, the mechanism for specifically inhibiting trans-translation but not translation is likely to reveal important differences between these reactions. In this context, the position of KKL-2098 on non-stop ribosomes was surprising. Binding of acylaminooxadiazoles could inhibit trans-translation by blocking tmRNA in the A site (Supplementary Fig. 6). However, given the similarities between the acceptor stems of tmRNA and tRNAs in the A site, why do molecules like MBX-4132 not inhibit translation in addition to trans-translation?

B

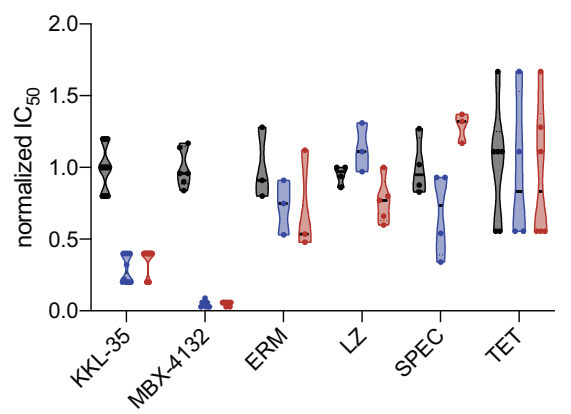

Fig. 4 Truncation of bL27 causes hypersensitivity to acylaminooxadiazoles. A Growth of $E$. coli $\Delta$ tolC expressing full-length bL27 (black) or variants missing residues $2-4\left(-3\right.$, blue) or 2-7 (-6, red) was monitored in broth microdilution experiments and the $\mathrm{IC}_{50}$ for MBX-4132 was determined. At least two technical replicates were performed for each biological replicate and the average of at least three biological replicates is shown with error bars indicating standard deviations. B Violin plot showing normalized mean $\mathrm{IC}_{50}$ values from at least 3 biological replicates of experiments as in (A) show that truncation of bL27 increases sensitivity to KKL-35 and MBX-4132 but has no effect on erythromycin (ERM), linezolid (LZ), spectinomycin (SPEC) or tetracycline (TET). Source data are provided as a Source Data file. 
A
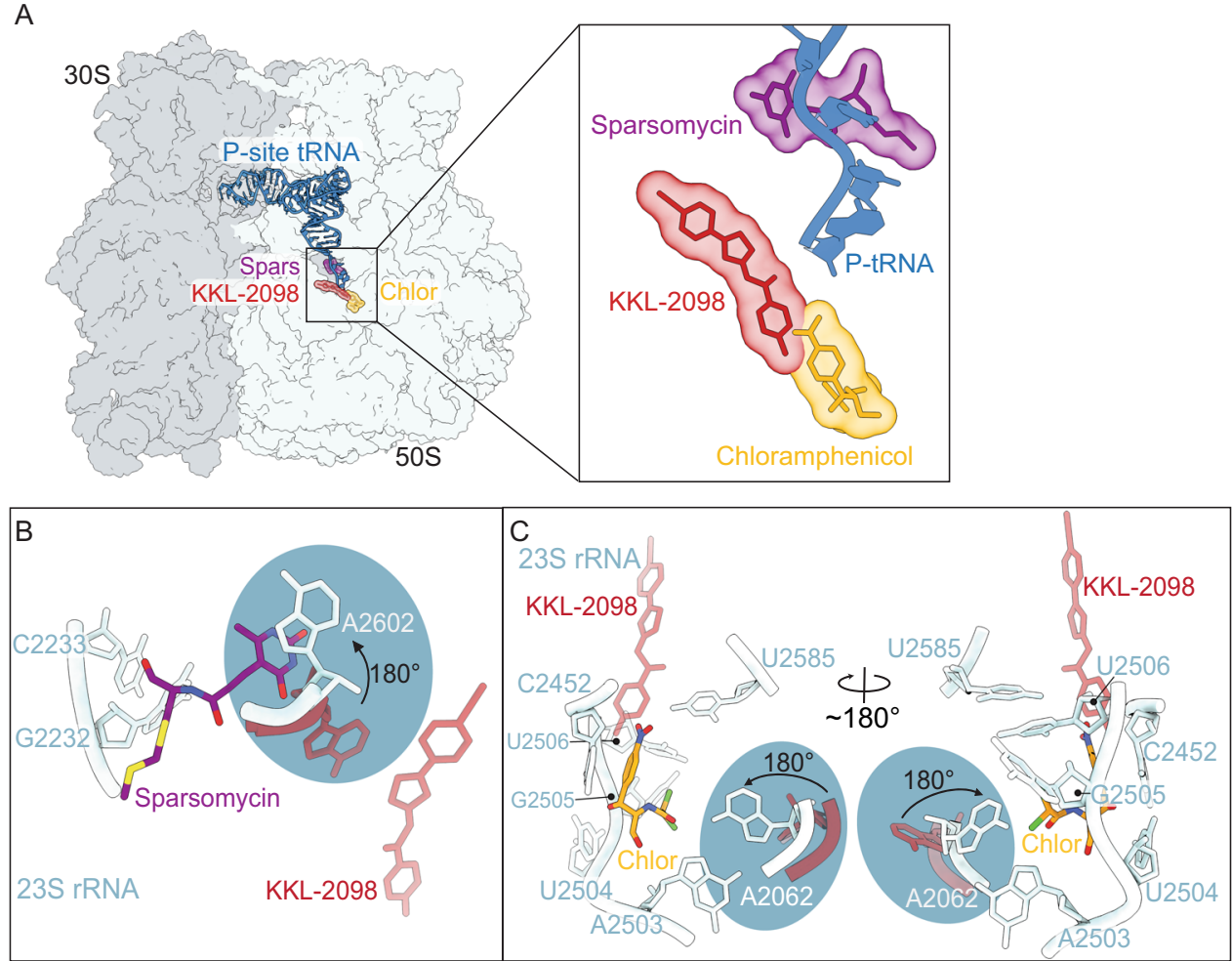

Fig. 5 Comparison of the position of KKL-2098 to other PTC inhibitors. A Overview of the bacterial ribosome showing the position of sparsomycin (PDB 1NJM), chloramphenicol (PDB code 6ND5) and KKL-2098. B Inset view of the interactions of PTC nucleotides with sparsomycin. The nucleobase of 23S rRNA A2602 moves $180^{\circ}$ upon sparsomycin binding. KKL-2098 and A2602 in the absence of sparsomycin binding are shown in red. C Inset view of the interactions of PTC nucleotides with chloramphenicol. The nucleobase of $23 \mathrm{~S}$ rRNA A2062 also moves $\sim 180^{\circ}$ upon chloramphenicol binding. KKL-2098 and A2062 in the absence of chloramphenicol binding are shown in red.

One possible explanation is the difference in the positions of tmRNA and tRNA as they translocate through the ribosome. The acceptor stems of tmRNA and tRNA are similar after accommodation in the A site, but there are slight differences after peptidyl transfer when the molecules adopt hybrid A/P states (Supplementary Fig. 6) ${ }^{27,28}$. Moreover, unlike tRNA, tmRNA can adopt a hybrid $\mathrm{A} / \mathrm{P}$ state without inducing rotation between the $50 \mathrm{~S}$ and $30 \mathrm{~S}$ ribosomal subunits, suggesting a substantial difference in the process of translocation (Supplementary Fig. 6) ${ }^{27,28}$. These differences between tmRNA and tRNA on the ribosome might allow MBX-4132 to specifically block tmRNA and thereby exclusively inhibit trans-translation.

The overall binding site of KKL-2098 is distinct from antibiotics that inhibit peptidyl transferase activity, including sparsomycin and chloramphenicol (Fig. 5). Binding of sparsomycin and chloramphenicol alters the conformation of critical PTC nucleotides. Sparsomycin binds close to the P-site tRNA (on the side closest to the $\mathrm{E}$ site) but on the opposite side of the P-site tRNA from chloramphenicol and KKL-2098 (Fig. 5B) ${ }^{29,30}$. Sparsomycin causes the nucleobase of universally conserved $23 \mathrm{~S}$ rRNA A2602 to rotate $\sim 180^{\circ 30}$. Chloramphenicol binds close to the CCA end of P-site tRNA and its binding causes the nucleobase of A2062 to rotate $\sim 180^{\circ 29}$. A2062 is also universally conserved and is important for sensing specific nascent chain residues in the exit tunnel that cause ribosome stalling ${ }^{31,32}$. In contrast, KKL-2098 binding is more distant from the PTC and does not induce changes in the positions of PTC nucleotides.

Conversely, binding of KKL-2098 alters the conformation of bL27 but antibiotics that target translation do not. The $\mathrm{N}$ terminus of bL27 is not resolved in most structures that do not contain an A-site ligand, including non-stop ribosomes without an inhibitor 22,33 , suggesting that the $\mathrm{N}$ terminus is mobile during translocation and accommodation of a new A-site ligand. In contrast, the presence of KKL-2098 in the non-stop ribosome stabilizes bL27 in the rotated conformation away from the PTC. If trans-translation specifically requires the $\mathrm{N}$ terminus of bL27 to be oriented toward the PTC, stabilization of the rotated conformation would be expected to inhibit trans-translation more than translation elongation. Alternatively, the acylaminooxadiazoles may specifically recognize subtle differences between non-stop ribosomes and translating ribosomes that are not observed in the structure described here. We note that the structural basis for the specificity of many ribosome-binding antibiotics has been difficult to discern ${ }^{34}$. For example, chloramphenicol binds in the A site near the PTC in a position that would appear to block any peptide-bond formation. However, many sequences are translated in the presence of chloramphenicol and inhibition depends on both the nascent polypeptide and the incoming amino acid ${ }^{35,36}$. Although further experiments will be required to test the models for specific inhibition of trans-translation, it is clear that the acylaminooxadiazoles exhibit a novel mechanism of antibacterial activity.

\section{Methods}

Chemical synthesis. All commercially obtained reagents and solvents were used as received. ${ }^{1} \mathrm{H}$ and ${ }^{13} \mathrm{C}$ NMR spectra were recorded on a Bruker $300 \mathrm{MHz}$ instrument. Chemical shifts are given in $\partial$ values referenced to the internal standard tetramethylsilane ${ }^{37}$. LC/MS analyses were performed on a Thermo-Finnigan Surveyor LC unit connected to a Thermo LTQ Fleet MS unit. HPLC purification was performed on a Gilson Unipoint instrument equipped with a 00G-4252-P0-AX $\mathrm{C} 18,10 \mu \mathrm{m}, 150 \mathrm{~mm}$ or $250 \mathrm{~mm} \times 21.2 \mathrm{~mm}$ column from Phenomonex. Silica column purification was performed on Isco brand Combi-flash $\mathrm{R}_{\mathrm{f}}$ liquid chromatography system using $50 \mu \mathrm{m}$ silica Luknova SuperSep columns. Melting points 
were taken on EZ-Melt automated melting point apparatus (Stanford Research Systems, Inc.) in manual mode, and are uncorrected. Thin-layer chromatography was performed on silica gel GHLF plates from Analtech (Newark, DE), and the chromatograms were visualized under UV light at $254 \mathrm{~nm}$. 5-(4-fluorophenyl)1,3,4-oxadiazol-2-amine, 3-phenyl-1,2,4-oxadiazol-5-amine were purchased from Enamine (Kiev, Ukraine); 5-phenyl-1,2,4-oxadiazol-3-amine was purchased from Chembridge (San Diego, CA, USA); 5-cyclohexyl-1,3,4-oxadiazol-2-amine, 1,3,4 oxadiazol-2-amine were purchased from Life Chemicals (Niagara-on-the-Lake, ON, Canada); p-Toluenesulfonyl Chloride, 1,1'-Carbonyldiimidazole were purchased from Thermo Fisher Scientific (Acros Organics) (New Jersey, USA); 4-Chlorobenzoyl chloride was purchased from Thermo Fisher Scientific (Alfa Aesar) (New Jersey, USA); 2-amino-5-phenyl-1,3,4-oxadiazole amine, 4Chlorobenzoic acid, Cyclohexanecarboxylic acid, 4-Chlorobenzaldehyde, Pyrrolidine, Piperidine, Hexamethyleneimine, Morpholine, Methyl Iodide, Sodium Triacetoxyborohydride, Diisopropylethyl amine, Triethylamine, and all solvents were purchased from Millipore-Sigma (St. Louis, MO, USA); 1,2,3,4-tetrahydro-isoquinoline and 4-chlorobenzene sulfonyl chloride were purchased from CombiBlocks (San Diego, CA, USA); 4-methyl-1,2,3,6-tetrahydropyridine hydrochloride was purchased from Pharmablock (Hatfield, PA, USA); HATU was purchased from GenScript (Piscataway, NJ, USA).

General method A. Heteroaryl amine (1.1eq) was dissolved in NMP (0.29 M) and triethylamine $(1.2 \mathrm{eq})$ stirred for $10 \mathrm{~min}$ at room temperature; to this solution, acid chloride (1 eq) was added dropwise via pipette. The reaction mixture was allowed to continue stirring at room temperature for $16-20 \mathrm{~h}$. If the reaction did not reach completion, the mixture was warmed to $50^{\circ} \mathrm{C}$ for an additional $16-20 \mathrm{~h}$. Upon completion, reaction mixture was added to water, and the resulting precipitate was filtered and dried. Crude precipitate purified with $\mathrm{HPLC}\left(5-95 \% \mathrm{MeCN} / \mathrm{H}_{2} \mathrm{O}+0.1 \%\right.$ TFA).

General method B. Carboxylic acid (1.1 eq) and HATU/HBTU (1.2 eq) were dissolved in NMP $(0.28 \mathrm{M})$, to which N,N-diisopropylethylamine $(1.2 \mathrm{eq})$ and heteroaryl amine $(1 \mathrm{eq})$ were added. The reaction was stirred at room temperature for 16-20 h. If the reaction did not reach completion, the mixture was warmed to $50^{\circ} \mathrm{C}$ for an additional $16-20 \mathrm{~h}$. Upon completion, reaction mixture was added to water, and the resulting precipitate was filtered and dried. Crude precipitate purified with HPLC (5-95\% MeCN/ $\mathrm{H}_{2} \mathrm{O}+0.1 \%$ TFA).

General method C. To oxadiazole amine (eq) and 1,1'-Carbonyldiimidazole (1 eq) in N-methyl imidazole $(0.56 \mathrm{M})$ was added $3 \AA$ molecular sieves $(1.6 \mathrm{~mm}$ pellets: $\sim 4$ pellets/mmol). Reaction was stirred at room temperature for $3-16 \mathrm{~h}$. Then, the second amine $(1.1 \mathrm{eq})$ was added to the reaction and continued stirring at room temperature for $2-18 \mathrm{~h}$. Upon completion, reaction mixture was added to water, and the resulting precipitate was filtered and dried. Crude precipitate was purified with HPLC (5-95\% $\mathrm{MeCN} / \mathrm{H}_{2} \mathrm{O}+0.1 \%$ TFA).

$K K L-35 / M B X-3535$. Prepared according to General Method A to provide material consistent with prior reports ${ }^{38} .15 .0 \mathrm{mg}(7 \%)$; mottled tan powder; ${ }^{1} \mathrm{H}$ NMR (DMSO): 12.35 (br, 1H), 8.08-8.01 (m, 4H), 7.65 (d, 2H), 7.47 (t, 2H); LC/MS: $318.0(\mathrm{M}+1)$; $\mathrm{mp}:>240{ }^{\circ} \mathrm{C}$ (decomp.); $\mathrm{R}_{\mathrm{f}}: 0.25$ (50\% EtOAc/hexanes).

MBX-4083. Prepared according to General Method A. $26.0 \mathrm{mg}$ (14\%); off-white solid; ${ }^{1} \mathrm{H}$ NMR (DMSO): 12.75 (br s, $\left.1 \mathrm{H}\right), 8.07-7.99(\mathrm{~m}, 4 \mathrm{H}), 7.67-7.58(\mathrm{~m}, 5 \mathrm{H})$; LC/MS: $300.0(\mathrm{M}+1)$; mp: $182-188^{\circ} \mathrm{C}$; $\mathrm{R}_{\mathrm{f}}$ 0.64 (50\% EtOAc/hexanes).

MBX-3943. Prepared according to General Method A. $12.0 \mathrm{mg}$ (6\%); white solid; ${ }^{1} \mathrm{H}$ NMR (DMSO): 11.77-11.68 (m, 1H), 8.14-7.91 (m, 4H), 7.76-7.53 (m, 5H); LC/MS: $300.2(\mathrm{M}+1)$; $\mathrm{mp}:>102{ }^{\circ} \mathrm{C}$ (slow); $\mathrm{R}_{\mathrm{f}}: 0.65$ (50\% EtOAc/hexanes).

MBX-3910. Prepared according to General Method A to provide material consistent with prior reports ${ }^{39} .30 .0 \mathrm{mg}(16 \%)$; white solid; ${ }^{1} \mathrm{H}$ NMR (DMSO): 12.26 (br, $1 \mathrm{H}), 8.08-7.96(\mathrm{~m}, 4 \mathrm{H}), 7.67-7.62(\mathrm{~m}, 5 \mathrm{H})$; LC/MS: $300.2(\mathrm{M}+1)$; mp: 250-259 ${ }^{\circ} \mathrm{C}$; $\mathrm{R}_{\mathrm{f}}: 0.34$ (50\% EtOAc/hexanes).

MBX-4370. Prepared according to General Method A to provide material consistent with prior reports ${ }^{38} .26 .0 \mathrm{mg}(28 \%)$; White solid; ${ }^{1} \mathrm{H}$ NMR (DMSO): 11.95 (bs, $1 \mathrm{H}$ ), 8.02-8.00 (m, 2H), 7.64-7.61 (m, 2H), $2.94(\mathrm{~m}, 1 \mathrm{H}), 2.02-1.98(\mathrm{~m}, 2 \mathrm{H}), 1.77-1.41$ (m, 8H); LC/MS: $306.2(\mathrm{M}+1)$; mp: $204-206^{\circ} \mathrm{C} ; \mathrm{R}_{\mathrm{f}}: 0.72$ (5\% MeOH/DCM).

MBX-4367. Prepared according to General Method A. $17.0 \mathrm{mg}$ (13\%); white solid; ${ }^{1} \mathrm{H}$ NMR (DMSO): 12.12 (bs, 1H), 9.10 (s, 1H), 8.06-7.98 (m, 2H), 7.65-7.59 (m, 2H); LC/MS: $224.0(\mathrm{M}+1)$; mp: $212-214^{\circ} \mathrm{C} ; \mathrm{R}_{\mathrm{f}}: 0.32$ (5\% MeOH/DCM).

MBX-C4227. Material was purchased and tested as received from Life Chemicals, Inc.

MBX-3709. Prepared according to General Method A. $150 \mathrm{mg}$ (97\%); light brown solid; ${ }^{1} \mathrm{H}$ NMR (DMSO): 11.66 (s, 1H), 7.99-7.95 (m, 2H), 7.47-7.41 (m, 2H),
1.87-1.66 (m, 6H), 1.41-1.22 (m, 6H); LC/MS: $290.0(\mathrm{M}+1)$; mp: $>205^{\circ} \mathrm{C}$ (slow); $\mathrm{R}_{\mathrm{f}}$ 0.73 (3.75:46.25:50 MeOH/EtOAc/DCM).

$M B X-3776$. Prepared in a manner analogous to that previously described ${ }^{40}$, by dissolving (E/Z)-N-(4-chlorobenzylidene)-5-(4-fluorophenyl)-1,3,4-oxadiazol-2amine $(0.331 \mathrm{mmol}, 1.0 \mathrm{eq})$, and $\mathrm{NaHB}(\mathrm{OAc})_{3}(0.430 \mathrm{mmol}, 1.3 \mathrm{eq})$ in dichloromethane $(1 \mathrm{ml})$, stirred at room temperature for $18 \mathrm{~h}$. Adsorbed material onto Celite and isolated product from column chromatography eluted with linear gradient of $0-50 \%$ EtOAc in Hexanes. $27.0 \mathrm{mg}$ (27\%); White solid; ${ }^{1} \mathrm{H}$ NMR (DMSO): 8.39 (t, 1H), 7.87-7.82 (m, 2H), 7.41-7.34 (m, 6H), 4.43 (d, 2H); LC/MS: 304.1 $(\mathrm{M}+1)$; mp: $165-167^{\circ} \mathrm{C} ; \mathrm{R}_{\mathrm{f}}: 0.42$ (50\% EtOAc/hexanes).

MBX-4076. Prepared by dissolving 4-chloro-N-(5-(4-fluorophenyl)-1,3,4-oxadiazol-2-yl)benzamide (MBX-3535, $0.220 \mathrm{mmol}, 1.0 \mathrm{eq})$ in DMF (2 ml), to which $\mathrm{K}_{2} \mathrm{CO}_{3}(0.264 \mathrm{mmol}, 1.1 \mathrm{eq})$ was added and the mixture was stirred at room temperature for $2 \mathrm{~h}$. Then methyl iodide $(0.220 \mathrm{mmol}, 1.0 \mathrm{eq})$ was added and continued to stir at room temperature for an additional $65 \mathrm{~h}$. The reaction was diluted with water $(\sim 30 \mathrm{ml})$, solid precipitate was filtered and dried under high vacuum. Product was purified by HPLC $\left(20-100 \% \mathrm{MeCN} / \mathrm{H}_{2} \mathrm{O}+0.1 \% \mathrm{TFA}\right)$ and freeze dried to solid. $13.0 \mathrm{mg}(18 \%)$; White solid; ${ }^{1} \mathrm{H}$ NMR $\left(\mathrm{CDCl}_{3}\right): 8.21(\mathrm{~d}, 2 \mathrm{H})$, 8.01-7.97 (m, 2H), $7.40(\mathrm{~d}, 2 \mathrm{H}), 7.22(\mathrm{t}, 2 \mathrm{H}), 3.74(\mathrm{~s}, 3 \mathrm{H})$; LC/MS: $332.2(\mathrm{M}+1)$; $\mathrm{mp}:>148^{\circ} \mathrm{C}$ (slow); $\mathrm{R}_{\mathrm{f}}: 0.66$ (50\% EtOAc/hexanes).

MBX-4063. Prepared according to modified General Method A; used solvent mixture of Pyridine/Dichloromethane (1/1 mixture) instead of NMP and trietheylamine. $33.0 \mathrm{mg}(18 \%)$; white solid; ${ }^{1} \mathrm{H} \mathrm{NMR}\left(\mathrm{CDCl}_{3}\right)$ : $7.96-7.86(\mathrm{~m}, 4 \mathrm{H})$, 7.34-7.16 (m, $4 \mathrm{H}+\mathrm{CHCl} 3), 2.42(\mathrm{~s}, 3 \mathrm{H})$; LC/MS: $334.1(\mathrm{M}+1) ; \mathrm{mp}: 218-221^{\circ} \mathrm{C}$; $\mathrm{R}_{\mathrm{f}}$ 0.14 (50\% EtOAc/hexanes).

MBX-4346. Prepared according to General Method C. $15.0 \mathrm{mg}$ (20\%); light yellow solid; ${ }^{1} \mathrm{H}$ NMR $\left(\mathrm{CDCl}_{3}\right)$ : 7.98-7.95 (m, 2H), 7.20-7.14 (m, 2H), $3.57(\mathrm{~m}, 4 \mathrm{H}), 1.96$ (m, 4H); LC/MS: $277.1(\mathrm{M}+1)$; mp: $197-199^{\circ} \mathrm{C} ; \mathrm{R}_{\mathrm{f}}: 0.94(10 \% \mathrm{MeOH} / \mathrm{DCM})$.

MBX-4699. Prepared according to General Method C. $13.0 \mathrm{mg}$ (9\%); white solid; ${ }^{1} \mathrm{H}$ NMR $\left(\mathrm{CDCl}_{3}\right)$ : 7.97-7.92 (m, 2H), 7.21-7.15 (m, 2H), $3.65(\mathrm{~m}, 4 \mathrm{H}), 1.62$ (m, 6H); LC/MS: $291.5(\mathrm{M}+1)$; mp: $200-203^{\circ} \mathrm{C} ; \mathrm{R}_{\mathrm{f}}: 0.64$ (10\% MeOH/DCM).

MBX-4700. Prepared according to General Method C. $15.0 \mathrm{mg}$ (33\%); white solid; ${ }^{1} \mathrm{H}$ NMR ( $\left.\mathrm{CDCl}_{3}+\mathrm{MeOD}\right): 7.92-7.88(\mathrm{~m}, 2 \mathrm{H}), 7.13-7.07(\mathrm{~m}, 2 \mathrm{H}), 3.48(\mathrm{~m}, 4 \mathrm{H})$, $1.69(\mathrm{~m}, 4 \mathrm{H}), 1.52-1.50(\mathrm{~m}, 4 \mathrm{H})$; LC/MS: $305.7(\mathrm{M}+1)$; mp: $191-194{ }^{\circ} \mathrm{C} ; \mathrm{R}_{\mathrm{f}}: 0.63$ (10\% $\mathrm{MeOH} / \mathrm{DCM})$.

MBX-4697. Prepared according to General Method C. $8.9 \mathrm{mg}$ (15\%); white solid; ${ }^{1} \mathrm{H}$ NMR ( $\left.\mathrm{CDCl}_{3}+\mathrm{MeOD}\right): 7.93-7.89(\mathrm{~m}, 2 \mathrm{H}), 7.18-7.12(\mathrm{~m}, 2 \mathrm{H}), 3.66(\mathrm{~m}, 8 \mathrm{H})$; LC/MS: $293.9(\mathrm{M}+1)$; mp: $211-216^{\circ} \mathrm{C}$; $\mathrm{R}_{\mathrm{f}}: 0.55$ (10\% MeOH/DCM).

MBX-4366. Prepared according to General Method C. $19.0 \mathrm{mg}$ (23\%); white solid; ${ }^{1} \mathrm{H}$ NMR $\left(\mathrm{CDCl}_{3}\right): 7.98-7.93(\mathrm{~m}, 2 \mathrm{H}), 7.21-7.16(\mathrm{t}, 2 \mathrm{H}), 5.41(\mathrm{~m}, 1 \mathrm{H}), 4.11$ $(\mathrm{m}, 2 \mathrm{H}), 3.78(\mathrm{~m}, 2 \mathrm{H}), 2.11(\mathrm{~m}, 2 \mathrm{H}), 1.73(\mathrm{~s}, 3 \mathrm{H})$; LC/MS: $303.0(\mathrm{M}+1)$; mp: $180-181^{\circ} \mathrm{C}$; $\mathrm{R}_{\mathrm{f}}: 0.74$ (5\% MeOH/DCM).

MBX-4132. Prepared according to General Method C; dried precipitate solids were triturated in $\mathrm{MeOH}(\sim 50 \mathrm{~mL})$ yielded pure product. $375 \mathrm{mg}(40 \%)$; white solid; ${ }^{1} \mathrm{H}$ NMR (DMSO): 7.98-7.94 (m, 2H), 7.46-7.40 (m, 2H), $7.19(\mathrm{~s}, 4 \mathrm{H}), 4.69(\mathrm{~s}, 2 \mathrm{H})$ 3.75 (t, 2H), 2.85 (t, 2H); LC/MS: $339.1(\mathrm{M}+1)$; mp: >190 ${ }^{\circ} \mathrm{C}$ (slow); $\mathrm{R}_{\mathrm{f}}: 0.51(50 \%$ EtOAc/hexanes).

Bacterial strains and growth conditions. Bacterial strains, plasmids, and synthetic sequences are shown in Supplementary Table 8. E. coli strains expressing bL27 ("b" indicates bacterial specific ribosomal proteins ${ }^{20}$ ) were constructed by transducing a tolC::cat allele into IW312 strains using a P1 vir phage. These strains were grown in LB medium containing $1 \mathrm{mM}$ IPTG. To quantify the in vitro antibacterial activity of acylaminooxadiazole analogs against various bacterial strains, the minimum inhibitory concentration (MIC) was measured using microbroth dilution assays as described in the CLSI guidelines (M7-A7) ${ }^{41}$, except that liquid G77L medium ${ }^{42}$ was used for Neisseria gonorrhoeae MIC assays. Each assay comprised three technical replicates, and each assay was repeated at least once. The reported MIC is the geometric mean of at least 5 technical replicates. $\mathrm{H} 041\left(\mathrm{STM}^{\mathrm{R}}\right)$ is a streptomycin-resistant derivative of the multi-drug resistant (MDR), ceftriaxone-resistant strain H041 (Ohnishi) and was cultured as previously described $15,18,43$

Time-kill assays. The time kill assay was performed essentially as described ${ }^{44}$ with the following modifications for N. gonorrhoeae. The bacterial inoculum for the assays was prepared by suspending colonies of $N$. gonorrhoeae ATCC 49226 grown on a chocolate agar plate for $>24 \mathrm{~h}\left(37^{\circ} \mathrm{C}\right.$ with $\left.5 \% \mathrm{CO}_{2}\right)$ in $\mathrm{G} 77 \mathrm{~L}$ medium. The cell 
suspension was adjusted to an $\mathrm{OD}_{600}$ of 0.1 and was diluted 1:10 in G77L media (final cell density $\sim 1 \times 10^{7}$ cells $/ \mathrm{ml}$ ) containing various concentrations of MBX4132. The resulting cultures were incubated at $37^{\circ} \mathrm{C}\left(5 \% \mathrm{CO}_{2}\right)$, and viability was monitored over $24 \mathrm{~h}$ by removing samples at various time points, making serial 10 -fold dilutions in G77L, and spotting $5 \mu \mathrm{l}$ of each dilution onto the surface of a chocolate agar plate in triplicate. Colonies were counted after the plates were incubated at $37^{\circ} \mathrm{C}\left(5 \% \mathrm{CO}_{2}\right)$ for $18-18 \mathrm{~h}$, colony forming units (cfu) per ml were calculated, and the average and standard deviation for the three replicates was determined. The lower limit of detection of this assay was determined to be $100-200 \mathrm{cfu} / \mathrm{ml}$. This experiment was repeated three times, and the results of a representative experiment are shown.

In vitro trans-translation and translation assays. The in vitro trans-translation assay is designed to produce the first 157 amino acids of nano-luciferase from a non-stop mRNA (nanoluc-ns) and add the C-terminal peptide AAVSGWRLFKKIS via a mutant version of $E$. coli tmRNA (tmRNA-nl) to reconstitute an active nanoluciferase ${ }^{45}$. In this assay, the tagged nano-luciferase gene has $>30,000$-fold increase in activity over the peptide made in the absence of tmRNA-nl.

S12 lysates were made according to the procedure of Kim, et al. ${ }^{46}$. Briefly, a culture of E. coli BL21 (DE3) cells containing a pET28 plasmid carrying the E. coli T7 polymerase gene was grown at $37^{\circ} \mathrm{C}$ to an $\mathrm{OD}_{600}=0.8$, induced with $1 \mathrm{mM}$ IPTG and grown for an additional $3 \mathrm{~h}$. Cells were harvested by centrifugation at $20,000 \times g$ for $10 \mathrm{~min}$ at $4{ }^{\circ} \mathrm{C}$ and the pellet was resuspended in buffer A $(20 \mathrm{mM}$ Tris-acetate ( $\mathrm{pH} 8.2), 14 \mathrm{mM} \mathrm{Mg}(\mathrm{OAc})_{2}, 60 \mathrm{mM}$ potassium glutamate, $1 \mathrm{mM}$ DTT). Cells were lysed by sonication, the lysate was clarified by centrifugation at $12,000 \times g$ for $10 \mathrm{~min}$, and the supernatant was stored at $-80^{\circ} \mathrm{C}$.

E. coli SmpB was purified as previously described ${ }^{3}$. tmRNA-nl, a variant of E. coli tmRNA encoding the final 11 residues of nano-luciferase, was transcribed from the tmRNA-nl synthetic DNA sequence in vitro, purified, and folded as previously described for wild-type E. coli tmRNA ${ }^{3}$. The nanoluc-stop template DNA was prepared as previously described ${ }^{3}$ by PCR amplification from pMC1 using T7 universal and nanoluc-stop primers. The nanoluc-ns was prepared in a similar manner using $\mathrm{pMC1}$ with $\mathrm{T} 7$ universal and nanoluc-ns primers.

For in vitro trans-translation, tmRNA-nl and SmpB were premixed and stored on ice. S12 lysate $(2 \mu \mathrm{l})$, freshly made polymix buffer $(2 \mu \mathrm{l})^{47}$ (final reaction concentrations $5 \mathrm{mM}$ Hepes pH 7.6, $5 \mathrm{mM} \mathrm{NH}_{4} \mathrm{Cl}, 0.5 \mathrm{mM} \mathrm{CaCl}_{2}, 1.5 \mathrm{~mm} \mathrm{MgCl}$, $1 \mathrm{mM}$ DTT, $8 \mathrm{~mm}$ putrescene, $2 \mathrm{~mm}$ ATP, $2 \mathrm{mM}$ GTP, $1 \mathrm{mM}$ CTP, $1 \mathrm{mM} \mathrm{UTP}$, $0.3 \mathrm{mM}$ each amino acid, $3 \mathrm{mg} / \mathrm{ml}$ E. coli tRNAs), nanoluc-ns template $(0.5 \mu \mathrm{l}$; $60 \mathrm{ng}$ ) and $2 \mu \mathrm{l}$ water were mixed and incubated at $37^{\circ} \mathrm{C}$ for $5 \mathrm{~min}$. This solution was dispensed to tubes containing $0.5 \mu \mathrm{l}$ of different concentrations of an inhibitor prepared in $75 \%$ acetonitrile, $25 \%$ water, and incubated at $37^{\circ} \mathrm{C}$ for $5 \mathrm{~min}$. The tmRNA-nl/SmpB mixture ( $0.5 \mu \mathrm{l}$ each, $2 \mu \mathrm{M}$ final) was added to each tube and the samples were incubated at $37^{\circ} \mathrm{C}$ for $1.5 \mathrm{~h}$. NanoLuc substrate (Promega) was prepared according to the manufacturer's instructions, one volume of this substrate solution was added to each sample tube, and the reactions transferred to a white 96-well plate. Luminescence readings were obtained using the SpectraMax i3 microplate reader. Data analysis was performed using GraphPad Prism 8.

Frequency of resistance. First, MIC values were determined for MBX-4132 using the reference agar dilution method ${ }^{41,48}$. N. gonorrhoeae strain 49226 (ATCC) was suspended to the equivalent of a 5 McFarland standard in G77L broth and then diluted to generate the final inoculum $\left(1.5 \times 10^{5}\right)$. The bacterial cell suspension was then transferred to wells in a stainless-steel replicator block which was used to inoculate the test plates. After the inoculum had dried, all plates were incubated at $35^{\circ} \mathrm{C}$ in $5 \% \mathrm{CO}_{2}$. The MIC was read post-incubation per CLSI guidelines ${ }^{41,48}$. To determine the frequency of resistance, stock solutions of MBX-4132 were prepared at $100 \mathrm{X}$ the final test concentrations of $4 \times$ and $8 \times$ the predetermined MIC value. A $0.5 \mathrm{~mL}$ aliquot of the $100 \mathrm{X}$ stock was mixed with $49.5 \mathrm{~mL}$ of molten GC Medium agar/1\% IsoVitaleX to produce an agar/drug mixture that was either 4 - or 8 -fold the MIC and dispensed into sterile $150 \times 15 \mathrm{~mm}$ plates (VWR) at a volume of $50 \mathrm{~mL}$ per plate. A dense cell suspension equivalent to $5 \mathrm{McF}$ arland was prepared using bacterial growth from $48 \mathrm{~h}$ chocolate agar plates of $N$. gonorrhoeae (ATCC 49226). The viable count of each suspension was determined by plating serial tenfold dilutions onto GC Medium agar/1\% IsoVitaleX in duplicate. A $0.25 \mathrm{ml}$ aliquot of inoculum was spread onto the surface of duplicate $150 \times 15 \mathrm{~mm}$ test plates. After allowing the inoculum to dry on the surface of the plate, the plates were inverted and incubated at $35^{\circ} \mathrm{C}$ (with $5 \% \mathrm{CO}_{2}$ ) for $48 \mathrm{~h}$. Colony counts were determined manually and the spontaneous mutation frequency was calculated using the following equation:

Average number of colonies from selection plates/Total number of cells inoculated. If there were no colonies on the antibiotic selection plates, the spontaneous mutation frequency was calculated as 1 /inoculum to indicate that the spontaneous mutation frequency was less than the limit of detection (one cfu).

Mammalian cell cytotoxicity $\left(\mathbf{C C}_{50}\right)$. The half maximal cytotoxic concentration $\left(\mathrm{CC}_{50}\right)$ of each compound against HeLa cells (ATCC CCL-2) was measured as previously described ${ }^{49}$. Each assay comprised three technical replicates, and each assay was repeated at least once. The mean values for each biological replicate were averaged, and the $\mathrm{CC}_{50}$ was determined using a 4-parameter nonlinear curve fitting algorithm (GraphPad Prism). The average of the $\mathrm{CC}_{50}$ s from two biological replicates was calculated and reported.

Liver microsome stability. To examine potential for first-pass metabolism of analogs in the liver, the stability of analogs in the presence of liver microsome preparations (Eurofins Discovery for human, dog and rat; Xenotech for mouse) was measured using the method of Kuhnz, et al. ${ }^{50}$. for murine studies and Oback for the dog, human and rat studies ${ }^{51}$. The amount of parent compound remaining after incubation with microsomes in the presence of NADPH over a 30 min time range was measured using a reverse-phase liquid chromatography/mass spectroscopy method that was customized for each compound. Half-lives were calculated using linear regression analysis of several time points.

Caco-2 permeability. To evaluate the potential for oral bioavailability, the ability of prioritized compounds to permeate a monolayer of Caco-2 (ATCC HTB-37) intestinal epithelial cells was determined as described ${ }^{52}$. Caco-2 permeability values $\left(\mathrm{P}_{\text {app }}\right)>1 \times 10^{-6} \mathrm{~cm} / \mathrm{sec}$ are predictive of oral bioavailability. The observation that $\mathrm{P}_{\text {app } \mathrm{A} \rightarrow \mathrm{B}}>\mathrm{P}_{\text {app } \mathrm{B} \rightarrow \mathrm{A}}$ indicates that efflux from the basolateral compartment does not occur.

Serum protein binding. Serum protein binding was determined using an equilibrium dialysis method as described ${ }^{53}$. The amount of compound in each chamber (buffer and serum) was measured using methods for reverse-phase liquid chromatography/mass spectroscopy methods that were customized for each compound.

Aqueous solubility. The maximum aqueous solubility of each compound was determined using a nephelometric method as described ${ }^{54}$. Each assay comprised three technical replicates, and each assay was repeated at least once. The reported solubility is the average of at least 5 technical replicates.

Cell-based non-stop luciferase reporter assay. To verify that MBX-4132 retains activity as an inhibitor of trans-translation, we measured its dose-dependent activity against the non-stop luciferase reporter assay strain E. coli SB75 $\Delta t o l C:: k a n$ (pluc-trpAt) essentially as described ${ }^{3}$, with modifications. Briefly, serial 1.5 -fold dilutions of MBX-4132 in DMSO were transferred to 96-well assay plates (Costar 3195), followed by the addition of $50 \mu \mathrm{l}$ of an overnight culture of SB75 $\Delta$ tolC::kan (pluc-trpAt) that had been diluted to a final $\mathrm{OD}_{600}$ of 0.4 with $\mathrm{LB}$ media supplemented with $100 \mu \mathrm{g}$ ampicillin/ml and $1 \mathrm{mM}$ IPTG. The final concentrations of MBX-4132 ranged from 0.05 to $1.5 \mu \mathrm{M}$, and the final concentration of DMSO was $2 \%$. The assay plates were incubated at room temperature for $2 \mathrm{~h}$, and $50 \mu \mathrm{l}$ of BrightGlo (Promega) bioluminescence reagent was added to each well. After 10 min incubation, bioluminescence intensity was measured using an Envision multi-label plate reader (Perkin Elmer). Each assay comprised three technical replicates, and the experiment was repeated three times. The fold induction for each MBX-4132 treated sample as compared to the DMSO-only sample was calculated for each technical replicate, and the average and standard deviation of the three technical was calculated. The $\mathrm{IC}_{50}$ was determined using a 4-parameter nonlinear curve fitting algorithm (GraphPad Prism).

\section{CYP450 inhibition, receptor panel profiling, and cardiac ion channel profiling} Several in vitro selectivity assays were performed at Eurofins Discovery Services using established methods and controls that behaved as expected (Supplementary Tables 5 and 6). For CYP450 inhibition assays, activity of MBX-4132 was tested at 5 concentrations from $30 \mathrm{nM}$ to $100 \mu \mathrm{M}$; no inhibitory activity $>50 \%$ was observed at any concentration. For receptor panel profiling, MBX-4132 was evaluated at $10 \mu \mathrm{M}$ and activity of $>50 \%$ (agonist or antagonist; note that negative \% inhibition indicates agonism) was scored as active.

Ames assay. The Ames assay was performed at SRI Biosciences, following the standard protocols established there ${ }^{55-57}$. In brief, samples were evaluated for their ability to induce genetic damage using the plate incorporation method with Salmonella typhimurium strains TA98 and TA100 with and without a metabolic activation mixture containing 10\% Aroclar-1254-induced rat-liver microsomes (S9). MBX-4132 was tested from a $5 \mathrm{mg} / \mathrm{mL}$ DMSO stock solution (the solubility limit), which provided plate concentrations up to $500 \mu \mathrm{g} /$ plate, with serial dilutions accessing doses as low as $5 \mu \mathrm{g} /$ plate. MBX-4132 precipitated at the two highest dose levels (500 and $100 \mu \mathrm{g} / \mathrm{plate}$ ), but at $50 \mu \mathrm{g} /$ plate, no precipitation was observed. Precipitation did not interfere with colony counts or analysis. Test articles were considered mutagenic when the mean number of revertant colonies increased in a dose-dependent manner. Some cytotoxicity was observed, but sufficient colonies were formed to allow analysis. As shown in Supplementary Table 6, MBX-4132 exhibited no significant deviation in revertant colonies from the DMSO control at any concentration tested. Data for 2-nitrofluorene and sodium azide (positive controls) and DMSO (negative control) were included for reference. 
Mitochondrial toxicity assays. Multiplexed cytotoxicity assay - Human primary hepatocytes were grown on collagen I coated optical plates, cultured in hepatocytes culture media in a humidified $5 \% \mathrm{CO}_{2}$ atmosphere at $37^{\circ} \mathrm{C}$. Cells were incubated in the presence of MBX-4132 at 10 concentrations starting a $100 \mu \mathrm{M}$ and serially diluted 3.16-fold for $24 \mathrm{~h}$ at $37^{\circ} \mathrm{C}$, incubated for $30 \mathrm{~min}$ with multiplexed fluorescent dyes (Hoescht, 6-carboxy-2',7'-dichlorodihydrofluorescein diazetat, and TMRE) and imaged to allow visualization of nuclei, reactive oxygen species generation, and mitochondrial oxidation. A $>3.5$-fold induction of ROS was considered consistent with formation of ROS and a $>2$-fold change in TMRE signal indicated an increase or decrease in mitochondrial membrane potential ${ }^{58}$.

Mitochondrial toxicity assay - HepG2 cells (ATCC) were seeded and cultured in media containing either glucose or galactose overnight. Test compounds were added at 8 concentrations (threefold serial dilution from $100 \mu \mathrm{M}$ to $30 \mathrm{nM}$ ) and incubated with the cells for $24 \mathrm{~h}$. Cell viability was measured by the alamarBlue method. The data in Supplementary Table 7 are inconsistent with MBX-4132 disrupting mitochondrial metabolic processes ${ }^{59}$. Assays were performed at Eurofins Cerep Panlabs.

\section{Pharmacokinetic analyses in mice}

For PO suspension dosing (Performed at Neosome LLC). Female CD-1 mice as above were fasted for $2 \mathrm{~h}$ prior, and $4 \mathrm{~h}$ after dosing. MBX-4132 was administered at $10 \mathrm{~mL} / \mathrm{kg}$ via oral gavage with a $1.0,2.5$, or $10.0 \mathrm{mg} / \mathrm{ml}$ suspension in vehicle A (5\% DMSO, 5\% Cremophor EL, $0.45 \%$ hydroxypropylmethylcellulose, $0.45 \%$ alginic acid, $22.5 \%$ hydroxy-betacyclodextrin). At $0.25,0.5,1,2,4,8$, and 24 h post dose, 3 mice from each group were euthanized by $\mathrm{CO}_{2}$ inhalation, blood was collected by cardiac puncture into $\mathrm{K}_{2}$ EDTA collection tubes, and protein was precipitated and analysed by LC/MS-MS for plasma concentrations of MBX-4132. Data were analysed using WinNonLin.

For IV and SC dosing (performed at Charles River Labs). MBX-4132 was administered at $6 \mathrm{ml} / \mathrm{kg}$ via direct tail vein puncture (IV, slow push) or subcutaneously to the intrascapular region (SC) in a $2 \mathrm{mg} / \mathrm{ml} 10 \%$ DMSO/80\% PEG-400/10\% water formulation. At $0.083,0.5,1,4,8$ and $24 \mathrm{~h}$ post dose, blood was collected from 3 mice/group by tail vein or facial bleed into $\mathrm{K}_{2}$ EDTA collection tubes, and protein was precipitated and analysed by LC/MS-MS for plasma concentrations of MBX-4132. Sampling was performed serially, with each mouse contributing sample at all time points. Data were analysed using WinNonLin.

Murine tolerability studies. Single dose tolerability studies - Female CD-1 mice were fasted for $2 \mathrm{~h}$ prior, and $4 \mathrm{~h}$ after dosing. MBX-4132 was administered at $10 \mathrm{ml} / \mathrm{kg}$ via oral gavage with a 0.0 (vehicle control), $1.0,2.5$, or $10.0 \mathrm{mg} / \mathrm{ml}$ suspension in vehicle A. Mice were observed at $0.083,0.25,0.5,1,2,5,8$, and $24 \mathrm{~h}$ post dosing, and any abnormal observations (behavior, agility, coat condition and appearance, color of urine, quality of feces, etc.) were noted. No abnormal observations of any dosing group were made during the $24 \mathrm{~h}$ course of this study. 4-6 weeks-old CD-1 female mice were received from Charles River laboratories and acclimated for at least 5 days prior to the start of the study. Apart from specific instances of fasting described in the experimental, the mice had free access to food and water. The animals were housed 3-6 per cage in a temperature and humiditycontrolled room with a $12 \mathrm{~h}$ light cycle. All procedures described are in compliance with the Animal Welfare Act, the Guide for the Care and Use of Laboratory Animals, and the Office of Laboratory Animal Welfare. These studies conform to the NeoSome IACUC policies and Operational Guidelines as approved by the IACUC membership, NeoSome Safety Officers, or Attending Veterinarian. All testing was performed at Neosome LLC.

Multidose tolerability studies - In preparation for this study, an abbreviated version of the above murine PK study using the same formulation (A) examined fasted mice vs. fed mice was performed, with plasma samples taken at 1 and $4 \mathrm{~h}$ post dosing and analyses as described in the PK section. No significant variation in exposure was observed at either timepoint.

Female CD-1 mice were given free access to food and water. MBX-4132 was administered to two groups of 3 mice for $7 \mathrm{~d}$ either QD (with compound) or BID, with an additional two groups of mice given only vehicle at $10 \mathrm{ml} / \mathrm{kg}$ via oral gavage with a $1.0 \mathrm{mg} / \mathrm{ml}$ suspension in vehicle A. Mice were observed visually twice daily for $10 \mathrm{~d}$ ( $3 \mathrm{~d}$ post final dose), additionally, mice were weighed once daily. Any abnormal observations (behavior, agility, weight, coat condition and appearance, color of urine, quality of feces, etc.) were noted. No abnormal observations of any dosing group were made during the $24 \mathrm{~h}$ course of this study. One mouse in the vehicle only group did exhibit a slight weight loss but had recovered weight by the end of the study.

In vivo efficacy testing in the gonorrhea mouse model. Groups of female BALB/ cAnNCr mice (Charles River Laboratories) (6-7 weeks old) were treated with $17 \beta$ estradiol and antibiotics (streptomycin and trimethoprim) to increase susceptibility to long-term $N$. gonorrhoeae infection as described ${ }^{15}$. Mice were inoculated vaginally with $N$. gonorrhoeae strain $\mathrm{H} 041\left(10^{4} \mathrm{cfu} /\right.$ mouse) two days after estradiol pellet implantation and vaginal swabs were cultured for 2 days post-bacterial inoculation to confirm infection. On the afternoon of the second culture day (day 0 ), mice were given MBX-4132, GEN or the vehicle ( $n=20-21$ mice/group). Doses of MBX-4132 were prepared fresh in vehicle at the time of treatment and administered as a single oral dose (dose volume $10 \mathrm{ml} / \mathrm{kg}$ ). The positive control GEN $(48 \mathrm{mg} / \mathrm{kg})$ was prepared and administered intraperitoneally as 5 daily doses as previously described ${ }^{15}$. Vaginal swabs were collected on 8 consecutive days following treatment and quantitatively cultured for $N$. gonorrhoeae to assess efficacy. The data are expressed as CFU/ml of vaginal swab suspension. Clearance was shown by Kaplan-Meier curves with log-rank (Mantel-Cox) statistical analysis. The average $\mathrm{cfu} / \mathrm{ml}$ over time was compared by 2-way ANOVA with Bonferroni posthoc analysis. Statistics were performed in GraphPad Prism Software. Mice were housed in Allentown cage units with $2-5$ animals per cage at $20-26^{\circ} \mathrm{C}$ with relative humidity $30-70 \%$ and a minimum of 10 air changes/h and $12 \mathrm{~h}$ light/12 h dark cycle. At the study endpoint (10 days post-inoculation), mice were euthanized using compressed $\mathrm{CO}_{2}$ gas in a $\mathrm{CO}_{2}$ gas chamber in the Laboratory Animal Medicine Facility. All animal experiments were conducted at the Uniformed Services University of the Health Sciences, a facility fully accredited by the Association for the Assessment and Accreditation of Laboratory Animal Care, under a protocol that was approved by the university's Institutional Animal Care and Use Committee.

Purification of stalled ribosome complexes. To construct pET28-H10arfArnc, a DNA cassette encoding 10 histidine residues, the M2 epitope, 3 glycine residues, and 20 arbitrary codons followed by 71 base pairs from the $3^{\prime}$ end of the E. coli arfA gene was synthesized and assembled into pET28 that had been digested with Ncol and HindIII ${ }^{60}$. The sequence from arfA contains the RNase III cleavage site ${ }^{61,62}$. Translation of the cleaved mRNA produces a 59 amino acid peptide with 10 histidines at the $\mathrm{N}$ terminus.

E. coli $70 \mathrm{~S}$ ribosomes were purified as described previously ${ }^{63}$. E. coli BL21(DE3) pET28-H10arfArnc cells were grown to an $A_{600}$ of $\sim 0.5$ in Luria broth (LB) medium at $37^{\circ} \mathrm{C}$ and induced with $1 \mu \mathrm{M}$ IPTG and $1 \mu \mathrm{M}$ KKL-2098 (synthesized as previously described ${ }^{11}$ ) and continued to grow for an additional hour at $37^{\circ} \mathrm{C}$ then cooled on ice for $20 \mathrm{~min}$. All centrifugation steps were performed at $4^{\circ} \mathrm{C}$. Cells were pelleted by centrifugation and washed with buffer 1 (10 mM HEPES-KOH, $\mathrm{pH} 7.6,10 \mathrm{mM} \mathrm{MgCl}_{2}, 1 \mathrm{M} \mathrm{NH}_{4} \mathrm{Cl}, 6 \mathrm{mM} \beta$-mercaptoethanol $\left.(\beta-\mathrm{Me})\right)$ twice and then resuspended in buffer 2 (10 mM HEPES-KOH, pH 7.6, $10 \mathrm{mM} \mathrm{MgCl}_{2}$, $100 \mathrm{mM} \mathrm{NH}_{4} \mathrm{Cl}, 6 \mathrm{mM} \beta$-Me). The cells were crosslinked under ultraviolet light $(254 \mathrm{~nm})$ for $10 \mathrm{~min}$, then lysed using an EmulsiFlex-C5 high-pressure homogenizer (Avestin). Cell debris was removed by centrifuging at $13,000 \times g$ for $15 \mathrm{~min}$. The lysate was further centrifuged at $27,000 \times g$ for $30 \mathrm{~min}$ to obtain the $\mathrm{S} 30$ fraction. Ribosomes were pelleted by centrifuging at $42,000 \times g$ for $17 \mathrm{~h}$. The pellets were resuspended in buffer 2 and bound to a $1 \mathrm{~mL}$ IMAC gravity column, washed with 10 column volumes of Buffer 2 and eluted with Buffer 2 supplemented with $500 \mu \mathrm{M}$ imidazole. Ribosomes were further purified over a $10-40 \%$ sucrose gradient in buffer 2 at $70,000 \times g$ for $12 \mathrm{~h}$. $70 \mathrm{~S}$ ribosomes were separated from polysomes and subunits using a Brandel gradient fractionator. The $70 \mathrm{~S}$ fractions were pooled, pelleted, resuspended in buffer 2 , and stored at $-80^{\circ} \mathrm{C}$.

Cryo-electron microscopy. UltrAuFoil ${ }^{\circledast}$ grids (Quantifoil, R1.2/1.3) were glowdischarged for $20 \mathrm{~s}$ with a Solarus 950 (Gatan). In total, $3 \mu \mathrm{l}$ of $70 \mathrm{~S}$ complexes at $100 \mathrm{nM}$ were placed on grids at $8{ }^{\circ} \mathrm{C}$ in $100 \%$ humidity and blotted for $3.5 \mathrm{~s}$ using a Vitrobot Mark IV (FEI).

Two independent datasets of 2,394 micrographs total (1863 and 531 micrographs, respectively) were collected on a Titan Krios (FEI) microscope operated at $300 \mathrm{kV}$ with a C2 aperture diameter of $70 \mu \mathrm{m}$. Movie frames were recorded at an accumulated dose of $58 \mathrm{e}-/ \mathrm{A}^{\circ}$ at a magnification of $59,000 \mathrm{X}$ (corresponding to a pixel value of $1.191 \AA$ ) with a DE-64 direct electron detector in counting mode ${ }^{64}$ using Leginon ${ }^{65}$ for automatic data acquisition. Images were recorded with a total exposure time of $19.3 \mathrm{~s}$, and intermediate frames were recorded every $0.2 \mathrm{~s}$ giving a total of 78 frames per image. Defocus values ranged from -1.3 to $-3 \mu \mathrm{m}$

Image processing. Pre-processing - All processing steps were carried out using Appion $^{66}$. All frames of each micrograph were aligned using MotionCor $2^{67}$. Contrast transfer function (CTF) parameters were estimated on all motioncorrected micrographs using CTFFIND $4^{68}$ and GCTF $^{67}$ and the best estimate chosen using resolution evaluation in Appion ${ }^{69} .197$ micrographs were excluded after manual inspection of corresponding power spectra displayed ice contamination, exposure to the shifted beam, or low-resolution Thon ring profiles. An initial set of $\sim 2000$ particles were picked using DoG (Difference of Gaussian) Picker ${ }^{70}$. A rotational average was generated from these picks, and this was used as a template for template-based picking using FindEM ${ }^{71}$. A total of 474,382 particles $(373,845$ and 100,537 particles from the first and the second dataset, respectively) were picked. Particles were extracted with a box size of $384 \times 384$ pixels in Appion.

Extracted particles from the two datasets were processed independently and combined after the last round of 3D reconstruction, and subjected to further 3D classifications and refinements in RELION-3 ${ }^{72}$ (Supplementary Fig. 2). Processing steps were initially performed on a $4 \mathrm{X}$-binned dataset.

Initial 3D refinement occurred against a $60 \AA$ low-pass filtered empty E. coli $70 \mathrm{~S}$ ribosome. $3 \mathrm{D}$ classification without alignment was used to discard free $50 \mathrm{~S}$ subunits. The resulting $70 \mathrm{~S}$ classes were combined and refined using an initial 
angular sampling of $7.5^{\circ}$ and local angular sampling of $1.8^{\circ}$ to improve angular assignment. Following refinement, another round of 3D classification without alignment was performed, with low resolution particles and particles containing Esite tRNA discarded. Two classes with an unrotated 70S were combined and subjected to refinement, followed by focused classification with a P-site mask. The P-site mask was generated from a 70S ribosome with P-site tRNA (PDB 4V4I) ${ }^{73}$, with a 5-voxel expansion and a 7-voxel soft edge. This resulted in a class of 70S particles with P-site tRNA. These particles were unbinned, refined, then underwent focused classification with an A site mask, created as stated, using a model of the $70 \mathrm{~S}$ ribosome with A-site tRNA (PDB 4V5D) ${ }^{23}$. Classes with P-site tRNA but no A-site tRNA were refined and post-processed.

Post-processing and beam-tilt correction. The resultant map was post-processed in RELION-3 using a solvent mask generated from the final reconstruction lowpass filtered to $40 \AA$ with a 7-pixel extension and 10-pixel soft edge. Beam-tilt estimation and correction was performed (without per-particle refinement of CTF parameters) using CTF refinement followed by 3D reconstruction. These steps were repeated iteratively until the highest resolution was achieved, and the final map post-processed with a solvent mask. Resolution estimations were calculated from Fourier shell correlations (FSC) at 0.143 between the two independently refined half-maps. Maps were sharpened in PHENIX ${ }^{74}$. The graphs of directional 3D FSC and global resolution of the maps were plotted using 3DFSC Processing Server ${ }^{75}$. Local resolution was estimated using blocres in Bsoft ${ }^{76}$.

Modeling. For initial model building, the coordinates of E. coli 70S ribosome (PDB 5MDV) were removed of P-site tRNA, E-site tRNA and mRNA and rigid-docked into cryo-EM maps using UCSF Chimera ${ }^{77}$. Ligand coordinates were initially generated in COOT using Lidia ${ }^{78,79}$. Ligand restraints were generated and edited in PHENIX eLBOW and REEL respectively ${ }^{80}$. P-site tRNA, mRNA, the N-terminus of bL27 and KKL-2098 coordinates were manually fit using COOT ${ }^{79}$. The P-site tRNA in PDB 5MDV was manually mutated to tRNA Gly, the last codon in the mRNA sequence. The assembled complex was then subjected to real space rigid body refinement followed by validation in PHENIX 1.17.1 ${ }^{80}$.

To model KKL-2098 into the map, two possible conformations were considered as potential orientation. The final placement was selected for three reasons. The most important reason was the orientation of the photoreactive azide linkage which cross-linked previously to $23 \mathrm{~S}$ rRNA $2452^{11}$. At the other end of the molecule, Zone 1 was the most tolerant of substitutions (Fig. 1) and its current placement indicated few interactions with the ribosome. Lastly, Zone 2 containing the oxadiazole was the least tolerant of changes and when Zone 1 and Zone 4 (containing the azide linkage) were positioned according to the first two rationales, KKL-2098 could make interactions with 23S rRNA A2602.

For the figures that show segmented maps (Supplementary Figs. 3D, 4, 5A,B, and 7A), the EM density map was low pass filtered to $5 \AA$ for the areas which were at an overall lower resolution, including the P-tRNA and KKL-2098 and Nterminus of L-27. The resulting EM density was segmented using a 2.5-3.5 ̊̊ radius mask around the desired residues in Chimera ${ }^{77}$. The segmented densities were exported to ChimeraX for enhancing graphical features ${ }^{81}$. For panels that include, $16 \mathrm{~S}$, L20, and 23S rRNA the sharpened map was used since they were higher resolution features. Other figures were made using the PyMOL Molecular Graphics System, Version 2.1 (Schrödinger, LLC).

Reporting summary. Further information on research design is available in the Nature Research Reporting Summary linked to this article.

\section{Data availability}

The data that support this study are included in this published article and its supplementary information files, or are available from the authors on reasonable request. Structural data have been deposited with PDB accession code 6OM6 and EMDB with accession code EMD-20121. Source data is provided with this article and is also available at https://doi.org/10.26207/p6nj-8v13.

Received: 9 September 2020; Accepted: 24 February 2021; Published online: 19 March 2021

\section{References}

1. Interagency Coordination Group on Antimicrobial Resistance. WHO $\mid$ No Time to Wait: Securing the future from drug-resistant infections. http://www. who.int/antimicrobial-resistance/interagency-coordination-group/finalreport/en/ (2019)

2. U. S. Department of Health and Human Services CDC. Cdc. Antibiot. Resistance Threats U. S. 2019, 148 (2019).
3. Ramadoss, N. S. et al. Small molecule inhibitors of trans-translation have broad-spectrum antibiotic activity. Proc. Natl Acad. Sci. USA. 110, 10282-10287 (2013)

4. Keiler, K. C. Mechanisms of ribosome rescue in bacteria. Nat. Rev. Microbiol. 13, 285-297 (2015)

5. Keiler, K. C. \& Feaga, H. A. Resolving nonstop translation complexes is a matter of life or death. J. Bacteriol. 196, 2123-2130 (2014).

6. Huang, C., Wolfgang, M. C., Withey, J., Koomey, M. \& Friedman, D. I. Charged tmRNA but not tmRNA-mediated proteolysis is essential for Neisseria gonorrhoeae viability. EMBO J. 19, 1098-1107 (2000).

7. Goralski, T. D. P., Kirimanjeswara, G. S. \& Keiler, K. C. A new mechanism for ribosome rescue can recruit RF1 or RF2 to nonstop ribosomes. mBio 9, 2123 (2018).

8. Chadani, Y., Ono, K., Kutsukake, K. \& Abo, T. Escherichia coli YaeJ protein mediates a novel ribosome-rescue pathway distinct from SsrA- and ArfAmediated pathways. Mol. Microbiol. 80, 772-785 (2011).

9. Feaga, H. A., Viollier, P. H. \& Keiler, K. C. Release of nonstop ribosomes is essential. mBio 5, e01916 (2014).

10. Shimokawa-Chiba, N. et al. Release factor-dependent ribosome rescue by BrfA in the Gram-positive bacterium Bacillus subtilis. Nat. Commun. 10, 5397 (2019).

11. Alumasa, J. N. et al. Ribosome rescue inhibitors kill actively growing and nonreplicating persister mycobacterium tuberculosis cells. ACS Infect. Dis. 3, 634-644 (2017)

12. Alirol, E. et al. Multidrug-resistant gonorrhea: a research and development roadmap to discover new medicines. PLoS Med. 14, e1002366 (2017).

13. Tisler-Sala, A., Ojavee, S.-E. \& Uusküla, A. Treatment of chlamydia and gonorrhoea, compliance with treatment guidelines and factors associatedwith non-compliant prescribing: findings form a cross-sectional study. Sex. Transm. Infect. 94, 298-303 (2018).

14. Jerse, A. E. et al. Estradiol-treated female mice as surrogate hosts for neisseria gonorrhoeae genital tract infections. Front. Microbiol. 2, 107 (2011).

15. Butler, M. M. et al. Aminomethyl spectinomycins as therapeutics for drugresistant gonorrhea and chlamydia coinfections. Antimicrob. Agents Chemother. 62, e00325-18 (2018)

16. Connolly, K. L. et al. Pharmacokinetic data are predictive of in vivo efficacy for cefixime and ceftriaxone against susceptible and resistant neisseria gonorrhoeae strains in the gonorrhea mouse model. Antimicrob. Agents Chemother. 63, e01644-18 (2019).

17. Schmitt, D. M., Connolly, K. L., Jerse, A. E., Detrick, M. S. \& Horzempa, J. Antibacterial activity of resazurin-based compounds against Neisseria gonorrhoeae in vitro and in vivo. Int. J. Antimicrob. Agents 48, 367-372 (2016).

18. Ohnishi, M. et al. Is neisseria gonorrhoeae initiating a future era of untreatable gonorrhea?: detailed characterization of the first strain with high-level resistance to ceftriaxone $\nabla$. Antimicrob. Agents Chemother. 55, 3538-3545 (2011).

19. Boström, J., Hogner, A., Llinàs, A., Wellner, E. \& Plowright, A. T. Oxadiazoles in medicinal chemistry. J. Med. Chem. 55, 1817-1830 (2012).

20. Ban, N. et al. A new system for naming ribosomal proteins. Curr. Opin. Struct. Biol. 24, 165-169 (2014).

21. Polikanov, Y. S., Steitz, T. A. \& Innis, C. A. A proton wire to couple aminoacyl-tRNA accommodation and peptide-bond formation on the ribosome. Nat. Struct. Mol. Biol. 21, 787-793 (2014).

22. Huter, P. et al. Structural basis for polyproline-mediated ribosome stalling and rescue by the translation elongation factor EF-P. Mol. Cell 68, 515-527.e6 (2017).

23. Voorhees, R. M., Weixlbaumer, A., Loakes, D., Kelley, A. C. \& Ramakrishnan, V. Insights into substrate stabilization from snapshots of the peptidyl transferase center of the intact 70 S ribosome. Nat. Struct. Mol. Biol. 16, 528-533 (2009).

24. Maguire, B. A., Beniaminov, A. D., Ramu, H., Mankin, A. S. \& Zimmermann, R. A. A protein component at the heart of an RNA machine: the importance of protein L27 for the function of the bacterial ribosome. Mol. Cell 20, 427-435 (2005).

25. Wower, I. K., Wower, J. \& Zimmermann, R. A. Ribosomal protein L27 participates in both $50 \mathrm{~S}$ subunit assembly and the peptidyl transferase reaction. J. Biol. Chem. 273, 19847-19852 (1998).

26. Wower, J. et al. Transit of tRNA through the Escherichia coli Ribosome: cross-linking of the $3^{\prime}$ end of tRNA to specific nucleotides of the $23 \mathrm{~S}$ ribosomal RNA AT THE A, P, AND E sites. J. Biol. Chem. 275, 37887-37894 (2000).

27. Rae, C. D., Gordiyenko, Y. \& Ramakrishnan, V. How a circularized tmRNA moves through the ribosome. Science 363, 740-744 (2019).

28. Loveland, A. B., Demo, G. \& Korostelev, A. A. Cryo-EM of elongating ribosome with EF-Tu.GTP elucidates tRNA proofreading. Nature 584, 640-645 (2020). 
29. Svetlov, M. S. et al. High-resolution crystal structures of ribosome-bound chloramphenicol and erythromycin provide the ultimate basis for their competition. RNA 25, 600-606 (2019).

30. Bashan, A. et al. Structural basis of the ribosomal machinery for peptide bond formation, translocation, and nascent chain progression. Mol. Cell 11, 91-102 (2003).

31. Koch, M., Willi, J., Pradère, U., Hall, J. \& Polacek, N. Critical 23S rRNA interactions for macrolide-dependent ribosome stalling on the ErmCL nascent peptide chain. Nucleic Acids Res. 45, 6717-6728 (2017).

32. Vázquez-Laslop, N., Ramu, H., Klepacki, D., Kannan, K. \& Mankin, A. S. The key function of a conserved and modified rRNA residue in the ribosomal response to the nascent peptide. EMBO J. 29, 3108-3117 (2010).

33. James, N. R., Brown, A., Gordiyenko, Y. \& Ramakrishnan, V. Translational termination without a stop codon. Science 354, 1437-1440 (2016).

34. Vázquez-Laslop, N. \& Mankin, A. S. Context-specific action of ribosomal antibiotics. Annu. Rev. Microbiol. 72, 185-207 (2018).

35. Choi, J. et al. Dynamics of the context-specific translation arrest by chloramphenicol and linezolid. Nat. Chem. Biol. 16, 310-317 (2020).

36. Marks, J. et al. Context-specific inhibition of translation by ribosomal antibiotics targeting the peptidyl transferase center. Proc. Natl Acad. Sci. USA. 113, 12150-12155 (2016).

37. Nguyen, S. T. et al. Structure-activity relationships of a novel pyranopyridine series of gram-negative bacterial efflux pump inhibitors. Bioorg. Med. Chem. 23, 2024-2034 (2015).

38. Kaur, J. et al. Optimization of a 1,3,4-oxadiazole series for inhibition of $\mathrm{Ca} 2+/$ calmodulin-stimulated activity of adenylyl cyclases 1 and 8 for the treatment of chronic pain. Eur. J. Med. Chem. 162, 568-585 (2019).

39. Yang, S.-J., Choe, J.-H., Abdildinova, A. \& Gong, Y.-D. A highly efficient diversification of 2-amino/amido-1,3,4-oxadiazole and 1,3,4-thiadiazole derivatives via reagent-based cyclization of thiosemicarbazide intermediate on solid-phase. ACS Comb. Sci. 17, 732-741 (2015).

40. Sakamoto, M., Miyazawa, K. \& Tomimatsu, Y. Addition reactions of heterocumulenes. II. 1, 4-cycloaddition reactions of diphenylketene with azadienes. Chem. Pharm. Bull. 24, 2532-2540 (1976).

41. Methods for dilution antimicrobial susceptibility tests for bacteria that grow aerobically: M07-A10; approved standard. (Committee for Clinical Laboratory Standards, 2015)

42. Macfarlane, D. E. \& Elias-Jones, T. F. Improved media for the culture of Neisseria gonorrhoeae. J. Med. Microbiol. 13, 597-607 (1980).

43. Ohnishi, M. et al. Ceftriaxone-Resistant Neisseria gonorrhoeae, Japan. Emerg. Infect. Dis. 17, 148-149 (2011).

44. Pillai S. K., Moellering R. C. \& Eliopoulos G. M. Antimicrobial Combinations. in Antibiotics in Laboratory Medicine, 5th ed. 365-440 (Lippincott Williams \& Wilkins, 2005).

45. Dixon, A. S. et al. NanoLuc complementation reporter optimized for accurate measurement of protein interactions in cells. ACS Chem. Biol. 11, 400-408 (2016).

46. Kim, T.-W. et al. Simple procedures for the construction of a robust and cost-effective cell-free protein synthesis system. J. Biotechnol. 126, 554-561 (2006).

47. Woolstenhulme, C. J. et al. Nascent peptides that block protein synthesis in bacteria. Proc. Natl Acad. Sci. 110, E878-E887 (2013).

48. Clinical and Laboratory Standards Institute. Performance standards for antimicrobial susceptibility testing. (2017).

49. Marshall, N. J., Goodwin, C. J. \& Holt, S. J. A critical assessment of the use of microculture tetrazolium assays to measure cell growth and function. Growth Regul. 5, 69-84 (1995).

50. Kuhnz, W. \& Gieschen, H. Predicting the oral bioavailability of 19nortestosterone progestins in vivo from their metabolic stability in human liver microsomal preparations in vitro. Drug Metab. Dispos. Biol. Fate Chem. 26, 1120-1127 (1998).

51. Obach, R. S. et al. The prediction of human pharmacokinetic parameters from preclinical and in vitro metabolism data. J. Pharmacol. Exp. Ther. 283, 46-58 (1997).

52. Hidalgo, I. J., Raub, T. J. \& Borchardt, R. T. Characterization of the human colon carcinoma cell line (Caco-2) as a model system for intestinal epithelial permeability. Gastroenterology 96, 736-749 (1989).

53. Banker, M. J., Clark, T. H. \& Williams, J. A. Development and validation of a 96-well equilibrium dialysis apparatus for measuring plasma protein binding. J. Pharm. Sci. 92, 967-974 (2003).

54. Bevan, C. D. \& Lloyd, R. S. A high-throughput screening method for the determination of aqueous drug solubility using laser nephelometry in microtiter plates. Anal. Chem. 72, 1781-1787 (2000).

55. Ames, B. N., Mccann, J. \& Yamasaki, E. Methods for detecting carcinogens and mutagens with the Salmonella/mammalian-microsome mutagenicity test. Mutat. Res. 31, 347-364 (1975).

56. Maron, D. M. \& Ames, B. N. Revised methods for the Salmonella mutagenicity test. Mutat. Res. 113, 173-215 (1983).
57. Mortelmans, K. \& Zeiger, E. The Ames Salmonella/microsome mutagenicity assay. Mutat. Res. 455, 29-60 (2000).

58. Abraham, V. C., Towne, D. L., Waring, J. F., Warrior, U. \& Burns, D. J. Application of a high-content multiparameter cytotoxicity assay to prioritize compounds based on toxicity potential in humans. J. Biomol. Screen. 13 527-537 (2008).

59. Marroquin, L. D., Hynes, J., Dykens, J. A., Jamieson, J. D. \& Will, Y. Circumventing the Crabtree effect: replacing media glucose with galactose increases susceptibility of HepG2 cells to mitochondrial toxicants. Toxicol. Sci. J. Soc. Toxicol. 97, 539-547 (2007).

60. Gibson, D. G. et al. Enzymatic assembly of DNA molecules up to several hundred kilobases. Nat. Methods 6, 343-345 (2009).

61. Chadani, Y. et al. trans-translation-mediated tight regulation of the expression of the alternative ribosome-rescue factor ArfA in Escherichia coli. Genes Genet. Syst. 86, 151-163 (2011).

62. Garza-Sánchez, F., Schaub, R. E., Janssen, B. D. \& Hayes, C. S. tmRNA regulates synthesis of the ArfA ribosome rescue factor. Mol. Microbiol. 80 1204-1219 (2011)

63. Zhang, Y., Hong, S., Ruangprasert, A., Skiniotis, G. \& Dunham, C. M. Alternative mode of E-site tRNA binding in the presence of a downstream mRNA stem-loop at the entrance channel. Struct. Lond. Engl. 1993 26, 437-445.e3 (2018)

64. Mendez, J. H., Mehrani, A., Randolph, P. \& Stagg, S. Throughput and resolution with a next-generation direct electron detector. IUCrJ 6, 1007-1013 (2019)

65. Suloway, C. et al. Automated molecular microscopy: the new Leginon system. J. Struct. Biol. 151, 41-60 (2005).

66. Lander, G. C. et al. Appion: an integrated, database-driven pipeline to facilitate EM image processing. J. Struct. Biol. 166, 95-102 (2009).

67. Zhang, K. Gctf: Real-time CTF determination and correction. J. Struct. Biol. 193, 1-12 (2016)

68. Rohou, A. \& Grigorieff, N. CTFFIND4: Fast and accurate defocus estimation from electron micrographs. J. Struct. Biol. 192, 216-221 (2015).

69. Sheth, L. K., Piotrowski, A. L. \& Voss, N. R. Visualization and quality assessment of the contrast transfer function estimation. J. Struct. Biol. 192 , 222-234 (2015)

70. Voss, N. R., Yoshioka, C. K., Radermacher, M., Potter, C. S. \& Carragher, B. DoG picker and TiltPicker: software tools to facilitate particle selection in single particle electron microscopy. J. Struct. Biol. 166, 205-213 (2009).

71. Roseman, A. M. FindEM-a fast, efficient program for automatic selection of particles from electron micrographs. J. Struct. Biol. 145, 91-99 (2004).

72. Scheres, S. H. W. RELION: implementation of a Bayesian approach to cryoEM structure determination. J. Struct. Biol. 180, 519-530 (2012)

73. Korostelev, A., Trakhanov, S., Laurberg, M. \& Noller, H. F. Crystal structure of a $70 \mathrm{~S}$ ribosome-tRNA complex reveals functional interactions and rearrangements. Cell 126, 1065-1077 (2006).

74. Adams, P. D. et al. PHENIX: a comprehensive python-based system for macromolecular structure solution. Acta Crystallogr. D. Biol. Crystallogr. 66, 213-221 (2010).

75. Tan, Y. Z. et al. Addressing preferred specimen orientation in single-particle cryo-EM through tilting. Nat. Methods 14, 793-796 (2017).

76. Heymann, J. B. Guidelines for using Bsoft for high resolution reconstruction and validation of biomolecular structures from electron micrographs. Protein Sci. Publ. Protein Soc. 27, 159-171 (2018).

77. Pettersen, E. F. et al. UCSF Chimera-a visualization system for exploratory research and analysis. J. Comput. Chem. 25, 1605-1612 (2004)

78. Emsley, P. Tools for ligand validation in Coot. Acta Crystallogr. Sect. Struct. Biol. 73, 203-210 (2017).

79. Emsley, P., Lohkamp, B., Scott, W. G. \& Cowtan, K. Features and development of Coot. Acta Crystallogr. D. Biol. Crystallogr. 66, 486-501 (2010).

80. Liebschner, D. et al. Macromolecular structure determination using X-rays, neutrons and electrons: recent developments in Phenix. Acta Crystallogr. Sect. Struct. Biol. 75, 861-877 (2019).

81. Goddard, T. D. et al. UCSF ChimeraX: meeting modern challenges in visualization and analysis. Protein Sci. Publ. Protein Soc. 27, 14-25 (2018).

\section{Acknowledgements}

We are grateful to Shura Mankin for providing bL27 mutants; Tim Murphy and the staff at Neosome Life Sciences LLC for support in performing and evaluating murine tolerability studies; Charles River Labs, for performing murine pharmacokinetic studies; Micromyx for performing MIC90 studies; Eurofins Panlabs, RTI International and SRI Biosciences for performing extensive in vitro safety screening studies. Funding and support for this research was provided by NIH grant R01GM121650 to K.C.K. and by NIAID preclinical contract services, NIH grant R43AI141132 to Z.D.A., and R01AI132276 to Z.D.A., and T32AI106699 to P.S. C.M.D. is a Burroughs Wellcome Fund Investigator in the Pathogenesis of Infectious Disease. The contents of this article are solely the responsibility of the authors and do not necessarily represent the official views of the Department of Defense or the Uniformed Services University. 


\section{Author contributions}

Z.D.A., M.C.T., J.S.B., S.C.C., S.M.K., L.R.M., M.M.B., T.J.O., and T.L.B. contributed medicinal chemistry design, compound synthesis, and evaluation of antibacterial spectrum, ADME, toxicity, and pharmacokinetics. A.M., E.D.H., P.S., S.M.S., and C.M.D. contributed structural analyses. J.N.A. synthesized KKL-2098 and contributed experiments with bL27 mutants. J.N.A., M.C., and K.C.K. contributed trans-translation assays. D.H. and M.C. made reagents to affinity purify non-stop ribosomes. K.L.C. and A.J. contributed mouse infection experiments. K.C.K., C.M.D., and Z.D.A. wrote the manuscript with contributions from other authors.

\section{Competing interests}

Authors Z.D.A., M.C.T., J.S.B., S.C.C., S.M.K., L.R.M., M.M.B., T.J.O., and T.L.B. are employees of Microbiotix, Inc. Authors Z.D.A., S.M.K., M.C.T., J.S.B., S.C.C., M.M.B., T.J.O., and K.C.K. are inventors on a provisional patent covering molecules MBX-4346, MBX-4699, MBX-4700, MBX-4697, and MBX-4132.

\section{Additional information}

Supplementary information The online version contains supplementary material available at https://doi.org/10.1038/s41467-021-22012-7.

Correspondence and requests for materials should be addressed to C.M.D. or K.C.K.
Peer review information Nature Communications thanks Charlene Kahler and the other, anonymous, reviewer(s) for their contribution to the peer review of this work.

Reprints and permission information is available at http://www.nature.com/reprints

Publisher's note Springer Nature remains neutral with regard to jurisdictional claims in published maps and institutional affiliations.

cc) Open Access This article is licensed under a Creative Commons Attribution 4.0 International License, which permits use, sharing, adaptation, distribution and reproduction in any medium or format, as long as you give appropriate credit to the original author(s) and the source, provide a link to the Creative Commons license, and indicate if changes were made. The images or other third party material in this article are included in the article's Creative Commons license, unless indicated otherwise in a credit line to the material. If material is not included in the article's Creative Commons license and your intended use is not permitted by statutory regulation or exceeds the permitted use, you will need to obtain permission directly from the copyright holder. To view a copy of this license, visit http://creativecommons.org/licenses/by/4.0/.

(c) The Author(s) 2021 